\title{
PARENT-CHILD INTERACTION IN THE ETIOLOGY OF DEPENDENT AND SELF-CRITICAL DEPRESSION
}

\author{
Sidney J. Blatt \\ Yale University \\ Erika Homann \\ University of Michigan
}

\begin{abstract}
The role of caring parent-child relationships in the development of depression has been investigated in three types of research strategies: (a) the study of secure and insecure attachment patterns in infants and young children; (b) the study of depressed mother-child interactions based on the assumption that the caring patterns in these families of children at risk for depression could contribute to the understanding of the etiology of depression; and (c) the study of normal and depressed adults' retrospective accounts of early caring experiences with their parents. A major conclusion from all three research methodologies is that mental representations or internal working models of attachment of care-giving relationships are central constructs in understanding the development of a vulnerability to depression. Secure and disturbed patterns of caring relationships are internalized by the child as mental representations; impaired mental representations based on disturbed relationships can create a vulnerability to later depression. There are suggestions that an anxious or ambivalent insecure attachment may lead to a depression focused on issues of dependency, loss, and abandonment, whereas an avoidant insecure attachment may result in a depression focused on issues of self-worth and self-criticism, with angry feelings directed toward both the caregiver and toward the self. Indications of possible critical periods in the development of vulnerability to depression are also considered.
\end{abstract}

From various theoretical perspectives and using very different research methodologies, several research teams have investigated the role of the parent-child relationship in the etiology of depression. They have independently concluded that impairments in "mental representations" (e.g., Blatt, 1974) or "internal working models" (e.g., Bowlby, 1980; Main, Kaplan, \& Cassidy, 1985) or care-giving relationships are a central construct in understanding the development of a vulnerability to depression.

Some research groups have studied attachment behavior in infants and young children

Correspondence should be addressed to Sidney J. Blatt, Departments of Psychiatry and Psychology, Yale University, 25 Park Street, New Haven, CT 06519. 
(e.g., Ainsworth, 1969, 1982; Main, 1983; Main, Kaplan, \& Cassidy, 1985) and considered how differences in attachment patterns might relate to the development of disordered behavior, including depression (Cicchetti \& Aber, 1986). Other research groups (e.g., the NIMH Collaborative Project-e.g., Cytryn et al., 1984; Davenport, Zahn-Waxler, Adland, \& Mayfield, 1984; Gaensbauer, Harmon, Cytryn, \& McKncw, 1984; ZahnWaxler, McKnew, Cummings, \& Radke-Yarrow, 1984; the Rochester Longitudinal Study-Sameroff, Seifer, \& Zax, 1982; Cohn \& Tronick, 1983, 1987; Field, 1984) have studied children of depressed mothers, based on the assumption that observing caring patterns in the families of these children at risk for depression could provide further understanding of the role of parent-child relationships in the etiology of depression. A third approach (e.g., Blatt, 1974; Blatt, Wein, Chevron, \& Quinlan, 1979; McCranie \& Bass, 1984; Parker, 1981, 1982, 1983) has studied adults' retrospective accounts of their early caring experiences and how differences in their recollections of their parents relate to current levels of depression. Results from these three research strategies indicate that both normal and disturbed parental caring patterns are internalized (or interiorized) in the child's mental representations of caring relationships, and that impaired mental representations of disturbed relationship patterns may create a vulnerability to later depression.

We review the findings from these three approaches to the study of parent-child interactions and consider how particular types of parent-child interaction patterns can create a vulnerability to depression in adulthood, with the assumption that disruptions of the attachment relationship with parents can lead to impaired mental representations of the care-giving relationships. These impaired cognitive schema are thought to interact with particular current psychological experiences and life events, which then immediately cause or precipitate depression (Cicchetti \& Aber, 1986; Cicchetti \& Schneider-Rosen, $1984 a, b)$. This interaction between vulnerability factors and contemporary stressful life experiences in creating depression becomes particularly apparent if depression is conceptualized, not in terms of clinical symptoms of depression (e.g., DSM-III-R), but on the basis of types of experiences that can provoke depressive reactions (Beck, 1983; Blatt, 1974; Blatt, Quinlan, Chevron, McDonald, \& Zuroff, 1982).

\section{TYPES OF DEPRESSION}

Several investigators from a variety of theoretical perspectives have recently differentiated between subtypes of depression based on the phenomenology of the experiences that lead individuals to become depressed. Blatt and his colleagues, from a developmental cognitive and psychoanalytic perspective (e.g., Blatt, 1974; Blatt, D'Afflitti, \& Quinlan, 1976, 1979; Blatt \& Shichman, 1983; Blatt et al., 1982), have differentiated two types of depression, an anaclitic and an introjective depression, and have discussed the developmental origins, predisposing personality characteristics, clinical manifestations, and the unconscious conflicts and defenses of these two types of depression. Anaclitic (or dependent) depression is characterized by feelings of loneliness, helplessness, and weakness; the individual intenscly and chronically fears being abandoned and left unprotected and uncared for. Thus, these individuals desperately need to keep in close physical contact with need-gratifying others, and they have deep longings to be loved, cared for, nurtured, and protected. Other people are valued primarily for the care, comfort, and satisfaction they can provide. Anaclitically depressed individuals rely intensely on others to provide and maintain a sense of well-being. Therefore, they have considerable difficulty with separation and loss and have great difficulty expressing anger for fear of destroying 
whatever need gratification others provide. Separation and loss, as sources of considerable apprehension, are often dealt with by primitive means, such as denial or a desperate search for immediate substitutes.

Introjective (or self-critical) depression, in contrast, is characterized by self-criticism and feelings of unworthiness, inferiority, failure, and guilt. Intense personal standards result in constant and harsh self-scrutiny and evaluation. These individuals have a chronic fear of disapproval, criticism, and of losing the acceptance and love of significant others. They constantly strive for excessive achievement and perfection, are often highly competitive and work hard, make many demands on themselves and sometimes achieve a great deal, but with little lasting satisfaction.

Generally, dependency has not been explored as fully as self-criticism, self-worth, and guilt in the research on depression. However, identification of this dimension of depression is consistent with the work of Seligman and his colleagues (Abramson \& Sackheim, 1977; Abramson, Seligman, \& Teasdale, 1978; Peterson, Schwartz, \& Seligman, 1984; Seligman, 1975) on learned helplessness and the feeling of being unable to control one's life as a central etiological issue in depression, as well as with the research by Hirschfeld, Klerman, Chodoff, Korchin, and Barrett $(1976,1977)$ on the importance of dependency in depression. Other researchers have made similar distinctions between these two types of depression. Beck (1983), elaborating a cognitive-behavioral model of depression, suggests sociotropy and autonomy as two prototypic themes in depression. An autonomously depressed individual is "permeated with the theme of defeat or failure," blames "himself continually for falling below his standards," and is "specifically self-critical for having 'defaulted' on his obligations" (Beck, 1983, p. 276). Beck (1983) describes sociotropic or socially dependent individuals as placing considerable importance on "positive interchange with other people," expressed in both "passive-receptive" wishes (acceptance, intimacy, understanding, support, guidance) and "narcissistic wishes" (admiration, prestige, status). Autonomous individuals are especially invested "in preserving and increasing [their] . . independence, mobility, and personal rights; freedom of choice, action, and expression; protection of his domain, and attaining meaningful goals" (Berk, 1983, p. 272). Whereas depression in the sociotropic individual "is most likely to occur ... in response to perceived loss or rejection in social relationships." Highly autonomous individuals are most likely to become depressed "in response to perceived achievennent failure or lack of control over the environment" (Robins \& Block, 1988, p. 848).

Bowlby $(1969,1973,1977,1980)$, from an ethological and object relations perspective, distinguished between "anxiously attached" and "compulsively self-reliant" individuals and their predisposition to depression. "Anxiously attached" individuals seek interpersonal contact and are excessively dependent on others; compulsively self-reliant individuals, in contrast, avoid others and are scornful of people who seek close, intimate interpersonal relationships. Bowlby speculates that excessive autonomy is a defense against re-experiencing early childhood frustration in caring relationships as a reaction to having been "parentified" children who prematurely assumed care-giving responsibilities in their family, often for their own parents.

Arieti and Bemporad (1978, 1980), from an interpersonal tradition, distinguished between "dominant other" and "dominant goal" types of depression, in which depression either focuses on wishes to be passively gratified by a dominant other or to be reassured of one's worth and to be free of guilt through attainment of a dominant goal. In the dominant other type of depression, children react to the experience of a sudden withdrawal of love and approval by developing a clinging, demanding, dependent, infantile relationship with the dominant other. In the dominant goal type of depression, children 
react to sudden withdrawal of love and approval by feeling they must submit to parents' expectations. The children seek to regain love and approval not only by being compliant, but by directing their entire effort toward a dominant goal which becomes an end in itself. When the dominant other is lost or the dominant goal is not achieved, depression results. These people feel dependent on others for support, direction, and a sense of well-being, and feel they lack the resources to establish a sense of meaning and purpose in life (Blatt \& Maroudas, in press).

These various theoretical positions all differentiate between two subtypes of depression based on the nature of the experiences that seem to precipitate depressive episodes, rather than on the severity or nature of the manifest symptoms. Each of these theoretical positions, although using somewhat varying terms, distinguishes between a depression initiated by untoward interpersonal events and a depression initiated by disruption in self-concept, achievement, or identity. These differentiations are consistent with recent formulations of a wide range of personality theorists who, using a variety of different terms, have discussed interpersonal relatedness and self-definition (e.g., attachment and individuation) as two central processes in personality development (e.g., Angyal, 1951; Bakan, 1966; Blatt, 1990; Blatt \& Blass, 1990; Blatt \& Shichman, 1983; McAdams, 1985; Shor \& Sanville, 1978; Spiegel \& Spiegel, 1978).

Blatt and Beck and their respective colleagues have developed procedures for assessing these two dimensions of depression. Blatt et al. (1979) constructed a scale containing 66 items derived from case-history reports of patients with affective disturbances (e.g., Cohen, Baker, Cohen, Fromm-Reichman, \& Weight, 1954), reflecting a wide range of experiences frequently associated with depression, but which were not themselves considered to be symptoms of depression. These iterns address details of the quality of the lives of depressed patients (e.g., how they relate to people, how they feel about themselves, the ways they conduct their lives). Using a 7-point Likert-type scale, individuals rate each question on how true each of the items is for them. Factor analysis (Blatt, D'Afflitti, \& Quinlan, 1976) of this Depressive Experience Questionnaire (DEQ) defined three orthogonal factors in males and females-dependency, self-criticism, and efficacy. Subsequent research indicated that these three factors are remarkably stable, have high internal consistency, and have substantial test-retest reliability (Zuroff, Quinlan, \& Blatt, 1990).

Factor 1, dependency, involves items that arc primarily externally directed. The items refer to interpersonal relationships and contain themes of being concerned about abandonment and losing people, feeling lonely and helpless, and wanting to be close to, related to, and dependent upon others. Concerns about being abandoned or rejected and about hurting or offending others lead to difficulties expressing anger and aggression for fear of losing the gratification that another can provide.

Factor 2, self-criticism, consists of items that are more self-reflective. These items express concerns about feeling guilty, empty, hopeless, unsatisfied, and insecure, having failed to meet expectations and standards, being unable to assume responsibility, threatened by change, feeling ambivalent about oneself and others, and tending to assume blame and to feel critical toward the self. The self-criticism factor correlates highly with traditional measures of depression, such as the Beck and the Zung depression scales. The dependency factor has only marginally significant correlations with these more traditional measures of depression and appears to assess a dimension of depression that is often overlooked in more usual methods of assessment. In an item analysis of the 20 items of the Zung Depression Scale, 14 items considered to assess psychological concerns, such as personal dissatisfaction, self-criticism, and hopelessness (Zung, 1972), correlated significantly $(p<.05)$ with the DEQ self-criticism factor. Six Zung items concerned with physical well-being, such as digestive functions, fatigue, psychomotor retardation, and 
irritability, correlated significantly with the DEQ dependency factor. These data suggest that dependent depressive concerns often appear in masked form (Lesse, 1974) or as depressive equivalents expressed in physical concerns and complaints.

In addition to identifying the two dimensions of depression-dependency and selfcriticism - the factor analysis of the DEQ identified a third factor called efficacy, which involves items indicating a sense of confidence about one's resources and capacities. There are themes of high standards and personal goals, responsibility, inner strength, feelings of independence, and pride and satisfaction in one's accomplishments. Individuals high on this scale are characterized by goal-oriented strivings and feelings of accomplishment, but not by an extreme competitiveness.

Beck and his colleagues (Beck, Epstein, Harrison, \& Emery, 1983) developed a Sociotropy-Autonomy Scale (SAS) for assessing these two dimensions of depression. Factor analyses of two 30-item self-report scales yielded two factors. One factor, sociotropy, consists of three subfactors or subscales reflecting concern about disapproval (10 items), attachment (13 items), and pleasing others ( 7 items). A second factor, autonomy, also consists of three subscales: achievement (12 items), freedom from control (12 items), and preference for solitude (6 items). Beck et al. (1983) and Robins (1985) reported good levels of internal consistency for the sociotropy and autonomy scales in both outpatients and undergraduates. The sociotropy and autonomy scales are only marginally intercorrelated, and Robins (1985) reported that the sociotropy scale correlated significantly with DEQ dependency $(r=.68)$ and that the autonomy scale correlated significantly with DEQ efficacy $(r=.39)$ but not with self-criticism.

In addition, recent research (Cane, Olinger, Gotlib, \& Kuiper, 1986; Mongrain \& Zuroff, 1989) has demonstrated that there are two subscales on the Dysfunctional Attitudes Scale (DAS) (Weissman \& Beck, 1978) that assess "Anaclitic and Introjective" dysfunctional attitudes (Mongrain \& Zuroff, 1989). Blaney and Kutcher (1991), in evaluating the relationships among the two factors of the DEQ SAS, and DAS, report high intercorrelations among the three scales assessing interpersonal relatedness (dependency, sociotropy, and factor 1 of the DAS). The relationships among the three scales designed to assess individuality (self-criticism, autonomy, and factor 2 of the DAS) are more complex, primarily because the autonomy scale of the Beck SAS appears to measure counter-dependency more than individuality (Blaney \& Kutcher, 1991). But the relationship between the DEQ self-criticism scale and factor 2 of the DAS is substantial.

One of the important questions to be addressed in research on depression is which specific conditions create vulnerability to different experiences of depression. We need to examine the antecedent conditions, the early life experiences, and resulting predispositions, which leave some individuals especially vulnerable to profound and persistent dysphoric feelings in reaction to current loss, disappointment, and failure. The study of insecurely attached children (e.g., Ainsworth, 1969; Main et al., 1985), children of depressed mothers (e.g., Cohn, Matias, Tronick, Connell, \& Lyons-Ruth, 1986; Field, 1984; Tronick \& Gianino, 1986), children at risk for depression (Cicchetti and Aber, 1986), and adults' retrospective accounts of their parents' attitudes and behaviors (e.g., Blatt, Wein, Chevron, \& Quinlan, 1979; Parker, 1979a, 1981), all indicate that impaired working models (Main et al,, 1985) or mental representations (Blatt, 1974) of self and others emerge from disruptive parent-child relationships and that these impaired schemata create an unusual vulnerability to depression.

These studies consistently suggest that depression is associated with a lack of parental care, nurturance, or support; with parental exercise of excessive authority, control, criticism, and disapproval; and/or with insecure attachment, such that the individual either constantly seeks reassurance and support and has difficulty with separation, or continu- 
ally anticipates rejection, criticism, and censure, and avoids interpersonal involvement. Data from the study of children raised by depressed mothers and of insecurely attached children furthermore suggest that these children have difficulty developing adaptive mental representations of interpersonal relationships, and that their parents, in struggling with similar issues from their childhood experiences with their own parents, are re-enacting their own difficulties in their childcaring patterns (Main et al., 1985).

This paper investigates to what degree depressions that focus on issues of interpersonal relatedness or of self-definition may each have their antecedents in disrupted parentchild relationships and thus be the results of insecure attachment with caregivers and the consequent impairments at certain stages in the development of object representations. A depression focused on interpersonal issues of caring and dependency would originate at a somewhat earlier developmental level when relationships are defined primarily in terms of disruptions and distortions of the caring relationship. This differs from a depression focused on more symbolic issues of self-definition, including concerns about self-worth, self-criticism, and issues of identity, which may originate somewhat later in development with the separation-individuation phase (Mahler, Pine, \& Bergman, 1975) and with the acquisition of language and the beginnings of conceptual thinking. These two types of depression, originating at different points in the developmental process, may therefore relate to different types of parental styles and be characterized by different types of impairments of the mental representations of the caregivers and the care-giving relationship.

While we argue that both dependent and self-critical depressions relate to disturbances in mental representations, the empirical literature has yet to establish when disturbances in mental representations specifically lead to depression and when other disorders are seen instead. While we offer some working hypotheses, further research still needs to uncover why some individuals with certain experiences become depressed, while others do not. The answers to this question will probably involve a complex interaction of numerous environmental and biological, as well as intrapsychic and interpersonal (dynamic) factors.

\section{THE ASSESSMENT OF MENTAL REPRESENTATIONS OF ATTACHMENT RELATIONSHIPS}

\section{Secure and Insecure Attachment in the Development of Mental Representations}

In the past decade there has been a surge of research on the attachment relationship between the infant and the caregivers and how various care-giving patterns lead to differences in the types of attachment and in the quality of mental representations. Much of this research is based on Bowlby's $(1969,1973,1980)$ theory of internal working models, as elaborated by Main et al. (1985). Main defines the internal working model as "a set of conscious and/or unconscious rules for the organization of information relevant to attachment and for obtaining or limiting access to that information, that is, to information regarding attachment-related experiences, feelings, and ideations" (pp. 66-67). Differences in the organization of attachment behaviors are conceptualized as "individual differences in the mental representation of the self in relation to attachment" (p. 67), which are

formed out of a history of the infant's actions, infant-parent interactions, and the fate of the infant's "attempts and outcomes", that is, the fate or outcome of the infant's efforts and intentions to regain the parent even in the parent's absence. The working model of the relationship to the attachment figure will reflect not an objective picture of "the parent" but rather the history of the caregiver's responses to the infant's actions or intended actions with/ 
toward the attachment figure. If this is true, then from the moment at which an animate or inanimate object can be represented there will be individual differences among infants in their internal working models of relationship to the attachment figure. (p. 75)

Disturbances in the child-parent patterns of interaction may become evident as early as 2 to 6 months of age (Beebe \& Lachmann, 1988; Cohn, Campbell, Matias, \& Hopkins, 1990) and continue to emerge throughout the rapprochement phase (Mahler et al., 1975) and the beginning development of evocative constancy (Fraiberg, 1969) during the second year of life. Highly stable differences in the security of attachment have been noted during the first year and a half of life (e.g., Ainsworth, Blehar, Waters, $\$$ Wall, 1978; Radke-Yarrow, Cummings, Kuczyinski, \& Chapman, 1985) and persist into later childhood (Ainsworth et al., 1978; Main, 1983; Main \& Weston, 1981; Main et al., 1985). Insecure attachment, as assessed between 12 and 24 months, interferes with the child's subsequent capacity to develop meaningful interpersonal relationships, to be able to trust others, and to develop a viable self-concept independent of the original attachment relationship (Kagan, 1981; Schneider-Rosen \& Cicchetti, 1984; Stern, 1985).

Attachment patterns observed in the second year of life remain remarkably stable over time when the environment also remains stable (Owen, Easterbrooks, Chase-Lansdale, \& Goldberg, 1984; Thompson, Lamb, \& Estes, 1982; Vaughn, Egeland, Sroufe, \& Waters, 1979; Waters, 1978), with an impressive relationship between the child's attachment patterns in infancy and a wide range of current and subsequent behavior. Securely attached 2-year-old toddlers, for example, are more enthusiastic, more cooperative with their parents, and more persistent when confronted with challenging tasks (Matas, Arend, \& Sroufe, 1978). Insecurely attached infants, in contrast, are rated subsequently as significantly less competent, show little enthusiasm in problem solving, do not use their parents' assistance effectively, and are less self-reliant (see also Londerville \& Main, 1981). Securely attached infants are described later in childhood as more socially confident, flexible, self-reliant, and curious than insecurely attached infants (Arend, Gove, \& Sroufe, 1979; Waters, Wippman, \& Sroufe, 1979), who are described as dependent, noncompliant, and aggressive, and who tend to seek attention in negative, defiant ways (see also Sroufe, 1983).

Qualities of the caregivers' rcsponses to their infants are also generally quite stable over time, with change in care-giving patterns most often being a function of significant changes in the level of stress in family life and in care-giving arrangements (Arend et al., 1979; Londerville \& Main, 1981; Matas et al, 1978; Vaughn et al., 1979; Waters et al., 1979). Patterns of infant attachment relate to the quality of the parent-child interaction. Sensitive and responsive caretaking throughout the first year of life leads to secure attachment (Bates, Maslin, \& Frankel, 1985; Egeland \& Sroufe, 1981; Main et al., 1985), while insecure attachment seems to relate to parental rejection of the infant's attempts at closeness and insensitivity to signals (Ainsworth, Bell, \& Stayton, 1971; Main et al., 1985). Attachment figures differ in the degree of comfort and ease they feel in physical contact with their children, in the frequency of their rejection of the infants' attempts for contact, and in the degree to which they respond harshly to their children's activities (Main, 1981; Main \& Goldwyn, 1984; Main \& Weston, 1981).

The caring relationships parents establish with their children are largely determined by the parents' own childhood experiences (Main et al., 1985), and the parents ${ }^{2}$ issues may be expressed in the relationship with their child at different times in the childrearing sequence. Caregivers overburdened by the young infant's dependency and demanding nature may be inconsistent, uncaring, inattentive, or overcontrolling, thus creating conflicts around dependency in their child. Other parents may feel more stress when their 
children are toddlers, and experience difficulty in dealing with the child's assertion of independence and autonomy, thus creating conflict in their child around issues of independence, assertion, self-worth, and self-definition.

Ainsworth et al. (1978), Main (1981), and Main et al. (1985) describe several types of insecure attachment, using mcasures of security of attachment to assess intcrnal working models of relationships in infants, 6-year olds, and adults. Assessment of infants' security between 12 and 18 months was based on classifications derived by Ainsworth et al. (1978), using observations of infants' behaviors in the Ainsworth "Strange Situation," while giving particular attention to the infants' behaviors toward their parent at reunion after brief (3-min) separations. Secure infants were described as showing some distress at separation from the caregiver, being easily comforted upon reunion, and interacting positively with the caregiver.

The first type of insecure attachment, Type A, is described as "insecure-avoidant," in which infants avoid their caregiver upon reunion after brief separation and especially avoid expressing anger or grief about the separation toward the caregiver. In a second type of insecure attachment (Type C), described as "insecure-ambivalent" (or resistant), infants have difficulties being comforted by their caregivers upon reunion, explore their environment very little, and are described by Sroufe (1983) as impulsive and helpless. Main and her colleagues (Main et al., 1985), in addition to the securely attached, insecure-avoidant, and insecure-ambivalent children (Ainsworth et al., 1978), also identified a fourth category constituting about $12 \%$ of the sample. These "Type D" infants demonstrated disorganized or disoriented patterns of attachment, in which they lack any clearly defined means of coping with separation and seemed instead to blend contradictory features of several strategies (e.g., strong proximity seeking followed by strong avoidance), or appeared dazed and disoriented upon reunion with the caretaker. Disorganization was clearly evident in a disordering of temporal sequences, incomplete or undirected movements, or confusion, apprehension, and depression. Main et al. tentatively concluded that children who displayed this "insecure-disorganized" pattern of separationreunion hehavior with their caretakers had internal working models of themselves in relation to attachment figures, which were qualitatively distinct from the internal working models that guided the behaviors of the secure, insecure-avoidant, or insecure-ambivalent infants.

Subsamples of the securely and insecurely attached infants were reassessed at 6 years old for their internal working models of their relationships with their parents. Main et al. (1985) recorded the children's verbal and affective responses to a separation anxiety test, consisting of 16 photographs of children ages 4 to 7 experiencing separations from their parents such as saying good night or saying goodbye to parents who are leaving for 2 weeks. The children were asked how they felt about the separation portrayed in the pictures. The verbal responses to the photographs were scored for "emotional openness," ranging from an easy balance between self-exposure and self-containment to a variety of insecure responses ranging from silence and an inability to express feelings spontaneously, to denial or marked disorganization. The behavior of these children was also observed at reunions after an actual hour of separation from their parents.

Main et al. (1985) also assessed the parents' internal working models of their attachment relationships with their own parents by using the Berkeley Adult Attachment Interview (BAAI), which evaluates the coherence of descriptions of attachment relationships and experiences, supportive and contradictory memories, and current evaluations of the experiences of early attachment relationships. Main et al. (1985) identified four major patterns. Adults rated as secure tended to see attachment relationships as influencing the development of their personality, and their descriptions of particular attachment 
relationships were reasonably balanced and objective. These securely attached parents tended to value attachment relationships and to discuss them freely and openly without apparent distortion. In contrast, adults rated as insecurely attached were of two types: they either discounted the importance of attachment relationships, or seemed to overvalue rclationships and to be entangled in ongoing dependency struggles with their attachment figures. A fourth group was also identified, consisting of individuals who had experienced the loss of a major attachment figure before they reached maturity and did not seem to have completed the mourning process.

Children who were classified as securely attached to the mother in infancy tended to have secure parents and were rated as emotionally open and as coping more constructively with separation at 6 years of age, saying, for example, that they would try to persuade their parents not to leave. This response was interpreted as indicating a representation of the relationship with the parents as one in which the children felt that their wishes and sadness about the separation could be communicated safely and effectively to their parents.

Children who were insecure-avoidant as infants also showed avoidant responses to family interactions at age 6; they directed their attention away from the parent after a separation (perhaps even moving away from the parent) and were uncomfortable discussing their feelings about separations in the Klagsbrun-Bowlby adaptation of the Hansburg's Separation Anxiety test (Klagsbrun \& Bowlby, 1976). For example, they "did not know" how a child could respond to a 2-week separation from the parents, and they "avoided, refused or turned around and away from ... a presented photograph of the family" (p. 96). The parents of these insecure-avoidant children were also rated insecure on attachment issues, and often "dismissed attachment relationships as being of little concern, value or influence" (Main et al., 1985, p. 91). Children of these parents seem to experience little response from their parents to their requests for closeness or attention. Such children could be left feeling ineffective and incompetent because of the futility in their efforts to establish gratifying interpersonal relationships (Schaffer \& Blatt, 1990).

Parents of insecure-ambivalent (Type C) infants seem "preoccupied" with dependency on their own parents and "still actively struggled to please them" (Main et al., 1985, p. 91). These infants display "strong and sometimes continual fear and distress, and seem constantly directed toward the parent and away from all other environmental features" (p. 74). Lack of attention to and exploration of the environment would limit these children's ability to learn skills for coping with stress or loss. These children, like their parents, seem preoccupied with maintaining contact with their parents as a source of emotional support and seem unable to turn to others to meet their needs for affection. They remain enmeshed with their parents in an intense dependent relationship, like the dependent type of depression seen in adults (Blatt, 1974; Beck, 1983). These children are unable to find comfort in their principal caregivers and presumably would lack the means for coping with stress or loss in adulthood, in part because they fail to form dependable attachments and therefore have weak support systems (Cicchetti \& Aber, 1986).

Disorganized children (Type D) display at 6 years a unique form of reunion behavior in which they did not reintegrate flexibly with their parents on reunion, but rather took charge of the interaction in a controlling fashion, either punitively or in a "pseudocaretaking" manner. In responses to questions about their feelings about separations, they would become "distressed, silent, irrational or occasionally self-destructive" (p. 96). They were, furthermore, the most likely to have parents who had experienced a loss of their own parents prior to their reaching maturity $(43 \%)$ or the loss of a sibling or another major attachment figure, other than the parent, with whom they had been raised $(52 \%)$. 
Main (1981) interprets the avoidance of the caretaker upon reunion in insecureavoidant children to be actually in the service of seeking proximity. The child is strongly motivated to seek proximity in order to reduce anxiety and increase security, but prior experience with the caretaking object has often been filled with events in which direct proximity-secking behavior or expression of anger clicitcd rcbuff or rejection from the caretaker. Thus, the avoidant response by the infant in the fairly stressful Strange Situation may be a compromise to stay within the mother's orbit, when the mother herself is threatening to the child. 'The child's avoidant response parallels the mother's tendencies to avoid intimate contact, particularly during moments of distress. The avoidant response, according to Main, also helps the child to organize and maintain some degree of selfcontrol over potentially disorganized and angry feelings and aggressive impulses. The displaced anger expressed by avoidant children (Main, 1981) and the insecurely attached children of depressed parents (Gaensbauer et al., 1984) may function similarly.

The relationships of the disorganized children with their parents seemed to be inverted - they were, in a sense, parents to their parents. Yet they had no set pattern of coping with their strong reactions to separation from their parents, or else their patterns represent a type of internal working model which has not yet been identified. The frequent history of loss of attachment figures for the parents of the insecure-disorganized children, coupled with the description of depressive responses in the behavior and affect of their 12- and 18-month infants in the Strange Situation, raises the possibility of specifying and empirically investigating a longstanding clinical hypothesis. This hypothesis suggests that the early experience of separation and loss is a major precursor for later depressive phenomena, especially a depression focused on feelings of loneliness and loss. One possibility is that later in development, these children may deal with their dependency needs by caring for others. They may become overcompensating, subtly hypomanic, seemingly efficacious individuals who deal with intense depressive dependent longings through denial and reversal (in Bowlby's terms, compulsive caregivers) by assuming responsibility for caring for others in ways they wish to be cared for (see also Blatt et al., 1982).

Disturbed relationships with the caregiver in infancy seem to become organized schematically according to the infant's experiences in interaction with the parent. Main et al. (1985) discuss that "where access [to the parent] is constantly restricted or admitted unpredictably we may expect active reorganization, restriction and redirection in attention, behavior, and emotional expression" (pp. 75, 77). The ongoing and internal nature of these schema is demonstrated by differences between secure and insecure infants and children in their behavior during separations from the parents and in 6-year olds' responses to projective questions. The schema's nature is also shown by the continuity of patterns of affect, cognition, and behavior over time in relation to attachment. The cognitive and affective manifestations of such "reorganization, restriction and redirection" are demonstrated in adults by the incoherence, inconsistency, and gaps observed in accounts of relationships given by parents rated as insecure on the BAAI, in contrast to the more fluent, objective, and coherent accounts given by parents rated as secure.

The concept of internal working models (c.g., Main ct al., 1985) is very similar to Stern's (1985) concept of generalized interactive experiences and the concept of mental representations discussed in the psychoanalytic literature - the conscious and unconscious mental schemata (including their cognitive, affective, and experimental components) of objects and events experienced in reality (Blatt \& Lerner, 1983). The quality of the infant-parent relationship, especially early experiences around attachment and separation, contributes substantially to the early form and quality of these mental representations. These early experiences of the self-in-relation to others lead to an increasingly 
consolidated sense of self and of the other as they are experienced in interaction. These generalized memory structures (with both conscious and unconscious components as well as affective and cognitive dimensions) create general expectations about subsequent interactions and determine modes of behavioral response-what Stern (1985) calls RIG's - generalized episodes of interactive experienccs. Thesc formulations about the internal mental models or levels of mental representations of caring relationships are consistent with recent emphasis on person schema and scripts in social psychology (e.g., Fiske \& Linville, 1980; Hastie, 1981; Higgins, 1989; Shank \& Abelson, 1977; 'Iaylor \& Crocker, 1987) and the emphasis on the importance of representation in cognitive theory (Blatt, 1990b, 1991a).

The normal development of evocative constancy in the second year enables children increasingly to separate from their caregivers with a sense of confidence and security. The more stable and positive the mother-infant relationship, the more secure and consolidated the child's sense of the mother and of him or herself in the mother's absence. The quality of attachment is closely related to the emergence of object constancy and of visual self-recognition (Stern, 1985), an early precursor of the developing sense of self (Schneider-Rosen \& Cicchetti, 1984); impairments in these dimensions of object constancy and sense of self appear to be central to the experience of depression.

The failure of insecurely attached children adequately to resolve separation-individuation from the parents and to establish a sense of self-definition and autonomy could lead to depression in two ways: (a) the failure to achieve a consolidated symbolic differentiation between self and caregiver means that even temporary disruption of the caring relationship is very disruptive to the child, and (b) failure to develop autonomy interferes with the child's confidence in being able to function independently and in asserting independence and individuality. The internalized representation of the parent as uncaring, undependable, and harshly critical, as well as of the self as vulnerable, weak, and ineffective, is re-experienced in other relationships, leading to generalized feelings of helplessness and hopelessness.

Certain apparent parallels can be drawn between the forms of insecure attachment as identified by Ainsworth and Main, and potential vulnerabilities to dependent and selfcritical depression. Excessive dependency has been implicated as a possible risk factor in depression (Bcmporad \& Wilson, 1978; Blatt, 1974; Blatt et al., 1976; Hirschfeld ct al., $1976,1977)$, and it is one of the two types of adult depression discussed by Blatt (1974), Bowlby (1973), Arieti and Bemporad (1980), and Beck (1983). Insecure-ambivalent infants and children, experiencing intensely enmeshed family relationships and having difficulty tolerating separations or in seeking support from the environment, could be vulnerable to a dependent (anaclitic or sociotropic) type of depression in adulthood. At 2 years the insecure-ambivalent children expressed anger more directly to their attachment figures than did avoidant children, but at $3 \frac{1}{2}$ years they were less enthusiastic and persistent, and more dependent on their caregivers for assistance than were insecureavoidant infants (Gove, 1982 in Sroufe, 1983). At $41 / 2$ years of age, such children were more impulsive and helpless and had particularly maladaptive responses to the loss of caregivers either by death or divorce (Bowlby, 1980).

The coping patterns of insecure-avoidant attachment, in contrast, seem more generally maladaptive and less clearly related to a specific type of depression, although aspects of insecure-avoidance do resemble elements of self-critical depression-an anhedonic, more stoic, autonomous, and isolated type of depression (Blatt, 1974). Gove (1982) observed that avoidant children expressed their anger indirectly by directing their anger at objects rather than people, or through subtle noncompliance. Preschool teachers described them as hostile, isolated, disconnected (Gove, 1982), and excessively dependent (Sroufe, 1983), 
were considered behavior problems by the fifth year of age (Erickson, Sroufe, \& Egeland, 1985), and had caregivers who provided little support and who had set unclear expectations and inconsistent limits in the earlier parent-child interactions. Note that both ambivalent and avoidant children are described as being dependent, the first with their caregivers, and the sccond in preschool. Thesc two cxpressions of dependency are consistent with behaviors observed in the Strange Situation, in which ambivalent infants cling to the caregivers while avoidant children avoid their caregivers but may be friendly to strangers (Main, 1981). Avoidant children who are able to form relationships with adults other than their primary caregivers may have better chances for healthy adult relationships than those children who remain "hostile, isolated and disconnected" (Gove, 1982) in all situations.

Similar attachment styles have been identified in adolescents and young adults (e.g., Hazan \& Shaver, 1987, 1990; Kobak \& Sceery, 1988; Shaver \& Hazan, 1987; West \& Sheldon, 1988; West, Sheldon, \& Reiffer, 1987), describing secure, avoidant (or dismissive), and anxious (or preoccupied) attachments. Secure attachments are characterized by mutuality and reciprocity, insecure-avoidant relationships are characterized by jealousy and fear, and insecure-anxious attachments are characterized by obsessions with the love object (Hazan \& Shaver, 1987, 1990) - what Freud (1914) described as an intense sexual attraction and a desire for union. Anxiously attached individuals are less socially competent and more symptomatic and anxious, while avoidant (or dismissively) attached individuals have positive self-representations (like securely attached individuals) but are rated by others as less socially adjusted, and as having more negative affect (especially hostility) and less insight and ego resilience (Kobak \& Sceery, 1988).

Fishler, Sperling, and Carr (1990), reviewing techniques available for the assessment of interpersonal relatedness in adults, conclude that there are two major approaches in this area: one from object relations theory and the other from attachment theory. Assessment from an object relations perspective is more fully developed, usually using more projective-type techniques with adult clinical samples and assessing primarily cognitiveaffective dimensions of mental representation. Assessment techniques from attachment theory have generally been based on direct observation of normal children, focusing on topologies of attachment behavior and applying these observations to behavior observed later in development (i.c., in later childhood, adolescence, and adulthood). Fishler et al. (1990) stress how an integration of these two approaches could enrich the study of interpersonal relatedness and establish longitudinal links between early childhood experiences and later behavior in adolescence and adulthood.

Zuroff (personal communication, 1990), in a study of adult attachment, reports that the large majority of male and female college students describe themselves on the Shaver and Hazan measure (1987) as securely attached. Avoidant-insecure attachment was more common in males whereas anxious attachment was more common in women. In fact, none of the 50 males in the Zuroff sample described himself as anxiously attached. Securely attached males and females had low scores of the DEQ dependency and selfcriticism factors, and higher scores on the efficacy factor. Avoidant females scored higher than controls on both dependency and self-criticisn, but especially on self-criticism. Anxiously attached females also scored higher than controls on dependency and selfcriticism, but especially on dependency. Avoidant males scores somewhat higher than controls on self-criticism and lower than controls on dependency. These data support the hypothesis that avoidant attachment is related to the development of self-critical attitudes, while anxious attachment is expressed in excessive dependency both in childhood and later in adolescence and adulthood.

The theory of internal working models of attachment relationships provides a rich and 
promising basis for understanding how early childhood experiences may set the stage for later difficulties. Farly caring relationships are central in forming the child's perceptions and understanding of interpersonal relationships and interactions, which when disturbed (e.g., insecure attachment) seem to produce vulnerability to difficulties later in childhood, and perhaps to depression or other disorders in adulhood. The process of prediction from childhood behavior to adult psychopathology is complex, since we do not yet understand the processes by which internal working models of different relationships are established and combined or generalized to new relationships. For example, while the working model of the attachment relationship with the mother seems first to be accessed by 6-year-old children's responses to measures of separation anxiety, 12- to 24-monthold infants do distinguish between their parents in their attachment behaviors (Main et al., 1985), and seem able to have different internal working models for different caregivers.

The complexity of the problem is compounded when one considers the possibility that an individual may have more than one working model of the same person, or of themselves (Zelnick \& Buchholz, 1990). Main (1990) has recently proposed that difficulties in adult relationships may arise when the child, in an effort to make sense out of confusing parental attitudes or behaviors, internalizes multiple conflicting models of the parent and his or her sense of self in relation to that parent. And while parental security or insecurity strongly corresponds to the quality of attachment observed in the child, we do not yet know what aspects of the parents' behaviors cause the transmission of disturbed working models, how the child's multiple working models of different relationships combine to create expectations of new relationships, nor which aspects of insecure attachment in childhood create predispositions to different forms of psychopathology in adulthood, although vulnerability seems likely in the various forms of insecure attachment. In the next section we look at these issues with regard to the role of parent-child interaction in the etiology of depression by examining the research on the interaction patterns of depressed mothers and their children.

\section{Children of Depressed Mothers}

Numerous investigators in the past 10 years have studied the childrearing practices of depressed mothers to identify various patterns of disrupted parent-child interactions that can distort the child's immediate and long-term development. These investigations extend and enrich findings from the study of variations of caring patterns seen in normal (nondepressed) mothers and how these variations lead to different types of insecure attachment. In this section we review the literature on the vulnerability to depression of children of depressed parents, as discussed in research on the epidemiology, life events, longitudinal studies, and mother-infant interaction of these families.

The study of depression in children of depressed mothers is an extension and elaboration of the studies of the impact of traumatic life events, particularly in childhood, as possible antecedents to psychopathology, especially depression. Estimates of prevalency rates for depression range from 5-15\% for adults (Boyd \& Weissman, 1982) to 1-9\% for children (Kashani et al., 1983), with various investigators indicating that depression can be diagnosed as early as 5 or 6 years of age (Cantwell \& Carlson, 1983; Rutter, Izard, \& Reed, 1986). Kovacs, Feinberg, Crause-Novack, Paulaskas, and Finkelstein (1984) have found that the early onset of depression in childhood predicts a more protracted depressive illness. Depressed third- to fifth-grade children report more recent life stressors, including more major family disruptions than nondepressed children of the same age (Beck \& Rosenberg, 1986). Several studies (see Lloyd, 1980) report higher incidences of stressful 
life events among adults in the year prior to onset of illness (Brown, Sklair, Harris, \& Birley, 1973; Paykel, 1982; Paykel, Prusoff, \& Meyers, 1975; Paykel \& Tanner, 1976; Paykel et al., 1970; Thompson \& Hendrie, 1972).

Studies of stressful life events, particularly childhood events, of depressed subjects as compared to controls, however, are contradictory or inconclusive (Cadoret, Winkur, Dorzab, \& Baker, 1972; Forrest, Fraser, \& Priest, 1965; Hudgeons, Morrison, \& Barchha, 1967; Lloyd, 1980; Perris et al., 1986) about whether certain life events actually cause depression, or whether the stress created by the events is compounded by an already existing vulnerability to depression (Richman \& Flaherty, 1987). Hirsch, Moos, and Reischl (1985) found that having a depressed parent interacts with experiencing stressful life events to contribute to depression in adolescents. Faravelli et al. (1986) note that it may be the meaning of particular life events for the individual that determines their long-term effect on depression. Thus, whilc depressive and control groups may experience similar life events, the reduced coping skills and support networks of the children of depressed parents may increase the likelihood of a depressive response to traumatic incidents (Cicchetti \& Aber, 1986; Faravelli et al., 1986). 'The propensity of a particular event to trigger a depressive episode may also depend on its resonance with areas of particular sensitivity in the individual, such as issues of self-worth, dependency, and separation or loss. These areas of vulnerability in turn may derive from previous life events, such as insecure attachment, death of a parent in one's childhood, or the experience of being raised by a depressed parent. Conversely, however, one should not underestimate the potential significance of environmental factors for an individual's development of a resilience or a resistance to vulnerability to depression. Resilient adolescent children of depressed parents, for example, appear to have established support systems outside of the family which they strongly valued (Beardslee \& Podorefsky, 1988). These resilient adolescents, through self-awareness and understanding, were able to separate themselves from the depressed parent's difficulties, many of them assuming caretaking roles for their parents.

In the past decade substantial research on children raised by mothers with clinical depression (e.g., Cicchetti \& Aber, 1986; Cicchetti \& Schneider-Rosen, 1984a, b; Cytryn et al., 1984; Egeland \& Sroufe, 1981; Emde, Harmon \& Good, 1986; Gaensbauer, 1982; Gaensbauer et al., 1984; Kashani et al., 1983; Klagsbrun \& Bowlby, 1976; Rutter, 1986) has consistently found the children (infants to pre-adolescents) to be at increased risk for psychiatric disorder, particularly depression. In a review of a segment of this research, Beardslee, Bemporad, Keller, and Klerman (1983) reported that approximately $40 \%$ of the offspring of depressed parents are diagnosed with depression or depressive symptoms. Onset of depression is earlier in these children than in controls, and after age 12, girls of depressed mothers are more likely to become depressed than are boys (Weissman et al., 1987). Children of depressed parents are also more likely than children of non-mentally ill parents to demonstrate other problems such as hyperactivity, attention deficit disorder, anxiety disorders, delinquency, substance abuse, truancy, enuresis, mania, and bulimia (Beardslee et al,, 1983; Kashani, Burk, \& Reid, 1985; Orvaschel, Weissman, \& Kidd, 1980; Weissman et al., 1987), and are at increased risk for suicide attempts (Friedman et al., 1984). Many of these behavioral disturbances observed in children of depressed mothers may be masked expressions of depression or depressive equivalents (Blatt, 1991b). Depressed children of depressed parents often experience disruptive, negative family environments, and may be abused in their homes. Hirsch et al. (1985) found that depressed adults both report discordant family environments in their childhoods and create similar homes for their own children. The literature clearly indicates these children's vulnerability to many forms of psychopathology. 
In characterizing depressed mothers, Davenport et al. (1984) found that affectively ill and healthy mothers did not differ in their rating of items about the child's learning, achievement, teaching, and discipline. One exception, however, was the item: "I think it's good practice for a child to perform in front of others," which depressed mothers endorsed significantly higher than nondepressed mothers. Depressed mothers were less likely to encourage openness to experience in their children, and they were less openly expressive of their own emotions about their children. Furthermore, depressed mothers were more likely than nondepressed controls to report themselves as experiencing negative affect toward their children and as tending to be overprotective. Home observations of parent-child interactions found depressed mothers to be "less active in interaction with their children and more disorganized, unhappy, tense, inconsistent, and ineffective" (Cicchetti \& Aber, 1986, p. 100). Sameroff et al. (1982) also noted that depressed mothers of 4-month-old infants were "less spontaneous, happy, vocal, and proximal to their child than non-mental-illness control mothers" (pp. 96-97). Thus, in both self-report and ratings by observers, depressed mothers differ from control mothers in their childrearing practices and their interactive style, but not in their expressed attitudes about childrearing practices.

While these mothers seem to display qualities of caretaking likely to be detrimental to the child, some mothers who are not depressed or who have other diagnoses may also show the same qualities of parenting, with similar effects. Goodman and Brumley (1990) compared high-risk, low socineconomic status (SF.S) schizophrenic, depressed, and well mothers, and found that in their sample depressed mothers fell between the schizophrenic and well mothers in the quality of parenting. While a lack of "maternal responsiveness and affectional involvenent" was strongly associated in all cases with poor social functioning in the children, regardless of maternal diagnosis, such a lack was most characteristic of schizophrenic mothers, followed by the depressed and well mothers. The authors did not speculate about the specificity of low maternal responsiveness and a lack of affectional involvement as a risk factor for depression or psychopathology. The Rochester Longitudinal Study (RLS) group, however, found that the children of depressed mothers showed less adaptive behavior than children of schizophrenic mothers, and both Rutter (1990) and Beardslee and Podorefsky (1988) have pointed out that the ability ot identify the parent as "ill," as in more severe forms of mental illness such as psychosis, may makc it easier for the child to understand and adjust to bizarre or irrational behavior. Egeland and Sroufe (1981) studied a group of mothers whom they described as "psychologically unavailable," and while these women were not formally diagnosed as clinically depressed, the descriptions of their interactions with their children closely resemble the withdrawn and controlling caretaking behaviors of depressed mothers. The mother's psychological unavailability deprives the infant of a feeling of security, but even when the mother is available, her lack of encouragement and her overprotectiveness discourage her child's exploration. Cicchetti and Aber (1986) raised the possibility that "perhaps psychological unavailability is one of the common features shared by some maltreating parents and most depressed parents which affect the security of the attached relationship between parent and the infant" (p. 102).

Cohn et al. (1986) described four patterns of interaction by depressed mothers with their infants. "Disengaged" mothers are predominantly unavailable and restricted in expression, corresponding to the traditional conception of depressed mothering patterns; "intrusive" mothers have high expressed anger and much physical poking and pulling at the infant (at least $25 \%$ of the time); "positive" mothers play with their infants and have positive expressions at least $35 \%$ of the time; and "mixed" mothers demonstrate little positive expression but show high rates of eliciting behaviors. Field, Healy, Goldstein, 
and Guthertz (1990) add a fifth category, "eliciting," in which the mother spends most time trying to elicit the infant's attention through "rapid and staccato" gestures. Field et al. found that $17 \%$ of the depressed mothers could be labeled intrusive, $29 \%$ disengaged, $25 \%$ eliciting, $8 \%$ positive, and $21 \%$ mixed, in contrast to the well mothers $(2 \%$ of whom werc intrusive, $2 \%$ discngaged, $33 \%$ eliciting, $43 \%$ positive, and $20 \%$ mixed). There were 24 depressed mothers and 24 well mothers, and all were low SES AfricanAmerican women. This heterogeneity among depressed mothers suggests that depressed mothers as a group are not uniformly withdrawn or disengaged, and also that the experience of having a depressed mother will not be the same for all children. It is possible that a disengaged mother will create greater difficulties for her child around experiencing the mother as a dependable caregiver, while the negatively intrusive mother may create conditions in which the child develops more avoidant reactions to protect himself from her intrusions, as well as having an increased preoccupation with issues of self-definition and self-worth.

A central working hypothesis of the various studies of mother-infant interaction has been that the depressed, unavailable, and rejecting mother influences her child through disruption or distortion of the child's development of normal interaction patterns, with both affective and cognitive consequences. Beebe and Lachmann (1988) describe motherchild relationships as ideally characterized by mutual responsiveness and matching, leading to positive affect in the infant, with feelings of efficacy and being understood (see also Schaffer \& Blatt, 1990). "Derailed" interactions, in which mother's responses do not match the infant's behaviors or do not correspond to the infant's needs, lead to reduced feelings of efficacy in the infant and misregulation of emotion (Tronick \& Gianino, 1986).

Studies of patterms of matching and contingent responsiveness of depressed versus well mothers and their infants suggest that the patterns seem to change as the infant develops. Cohn and Tronick (1987) describe 3-, 6-, and 9-month-old normal infants in a crosssectional study as showing increasing differentiation and flexibility in their shared states with their mothers. Comparisons of various studies of infants of depressed mothers seem to suggest that at 2-3 months of age there is affective matching and contingent responsiveness, though most often in negative states (Field et al., 1990), but at 6 months this is less true. The depressed mother-infant dyads in Cohn et al. (1986) seldom played together, the 6-month-old infants were generally withdrawn with little positive expression or attention to objects, and there was a "general lack of contingent responsiveness, . . . [and] little indication of turn-taking" between the mother and child (p. 39), while over half of normal mothers and a third or more of their infants at 6 months tended to show contingent responsiveness (Cohn et al., 1986). Cohn et al. (1990) write "taken together, these findings suggest a shift with development from contingent responsiveness at 2 months to an attenuated involvement with persons and objects later in the first year" (p. 21). Furthermore, normal 3-month-old infants' depressed moods in response to simulated depression have been shown to generalize to other, nondepressed interactions (Cohn \& Tronick, 1983; Field, 1984), and depressed infants' moods generalize to interactions with nondepressed women (Field et al., 1988, 1990). Field et al. (1990), however, point out that when the mother's depression has improved by 6 months, the infant's has too, and that "if mood states are shared, if the mother appears to be leading these early interactions, and if the infant is resilient, it is not surprising that the infants' mood states may change as the mothers' moods change" (p. 13).

Beebe and Lachmann (1988) describe how patterns of interaction between mother and child become internalized by the young infant in the form of expectations of interaction patterns. These expectations are based on the infant's experience of mutual responsiveness, contingency, and the matching of direction, affective content, and temporal patterns 
in interaction with the mother. Infants as young as 3 months of age notice changes in their mothers' behavior (Cohn \& Tronick, 1987), such as when the normal mother is instructed to simulate a depressed mood. The infants modify their behavior in response to this change in the mother's behavior, with both positive and negative eliciting behaviors, such as brief smiles and glances, or crying (Cohn \& Tronick, 1983; Field et al., 1990). Furthermore, infants who experienced more mutual regulation or repairs of interactive errors in a normal interaction with their mothers tried more persistently to establish contact with their depressed-acting mothers than infants without such experience (Tronick \& Gianino, 1986). In contrast, infants of depressed mothers showed no change in behavior in response to their mothers' "simulated" depressions (Field, 1984), suggesting that in both normal and depressed infants some sort of early representation or schema of the mother's behavior is carried over from moment to moment, and that the infant's affective and behavioral reactions to the mother's behavior are influenced by the infant's history of prior experience with the mother. Such representations are also suggested by Yarrow and Goodwin (1973), who found that a change in the mothering figure caused by moving infants 3-16 months of age from a foster placement to an adopting mother seemed to cause disruption of social, emotional, and cognitive capacities, increasing in frequency and severity with age, and with "the state of development of a focused relationship with the mother figure" (p. 1039).

Beebe and Lachmann (1988) cite several studies finding correspondences between mother and infant interactional tendencies at 2-4 months and infant attachment at 1 year, in which positive infant behaviors at 2-4 months were associated with secure attachment at 1 year, and looking away, fussiness, and unresponsiveness at 4 months were associated with anxious attachment at 1 year (Blehar, Liebermann, \& Ainsworth, 1977). In a number of studies, maternal sensitivity and contingent responsiveness in the first months of the infant's life variously predicted infant cognitive and social competence and secure attachment at 1 year, and a longitudinal study (Reich, 1988) found continuity of interaction structures and patterns from 4 to 24 months. The increased looking away, fussiness, and protest seen in young infants of depressed mothers and in infants of normal mothers who are simulating depressed expressions also recall the avoidant and ambivalent behaviors seen in the older insecurely attached infants observed in the Ainsworth Strange Situation. These continuities strengthen the assumption that the infant bchaviors seen in the face-to-face interactions with their mothers serve self-regulating and attachmentoriented functions, and that patterns learned, preferred, or resorted to in infancy create a greater tendency later in life to return to those states in times of stress, separation, or insecurity.

Longitudinal studies of infants and children at risk for depression address the caretaking environment and the general quality of the parent-child interaction to evaluate the temporal and behavioral specificity of the impact of a parent's pathology on the child's developmental processes. While it has not yet been possible to draw one-to-one correspondencies between psychopathology in parents and psychopathology in their children, certain elements of negative parenting which are commonly found in depressed parents seem to be linked with problems experienced by the children. Longitudinal studies permit observation of the development of psychological symptoms from early structures to more organized and symbolic processes in which early forms of psychopathology are transformed over the course of development into more structured, adult forms of pathology (Werner, 1948). These longitudinal studies are often based on the assumption of "sensitive periods" in which differential vulnerability occurs as a consequence of various types of insult that can occur at different stages in the developmental process. Two extensive longitudinal studies of children of depressed mothers, the RLS (Sameroff et al., 1982) 
and the NIMH/Colorado Collaborative Studies (Cytryn et al., 1984; Davenport et al., 1984; Gaensbauer et al., 1984; Zahn-Waxler et al., 1984), not only suggest that having a depressed mother leaves a child at risk for depression (see also Cantwell, 1983; Coyne et al., 1987; Gershon, Bunney, Leckman, Van Eerdewegh, \& DeBauche, 1976), but also hclp us to begin to pinpoint critical points at which disruptions in attachment and cognitive development can occur.

The RLS research group studied four groups: children of schizophrenic mothers $(N=29)$, mothers who were neurotically depressed $(N=58)$, mothers with personality disorders $(N=40)$, and a group of mothers without evidence of mental illness $(N=57)$. They studied the impact of maternal diagnosis, severity and chronicity of illness, and family social status on the child's adaptive behavior. They found that family social status had stronger effects on children's early development than did mental illness variables, such as diagnosis, severity, and chronicity of mother's disturbance, accounting for a substantial portion of the variance in the developmental quotients and home observations of the child's adaptive behavior. The mothers of low-SES African-American families, in comparison to African-American high-SES and white low-SES mothers, showed less positive affect and were less involved in interacting with their children (Sameroff et al., 1982, p. 62). Partialling out social status, the next most powerful predictor of the children's early development was the severity and chronicity of the mother's illness. The specific psychiatric diagnosis of mother's disturbance was the least influential of the four risk factors, although, as already noted, the children of neurotically depressed mothers did less well than children of schizophrenic mothers when compared to children of mothers with no mental illness.

Gaensbauer and his colleagues (1984) compared at 12,15, and 18 months of age, seven male index children of manic-depressive and unipolar depressed parents with seven children of parents without psychiatric diagnosis, matched on age, race, and SES. They observed the children's security of attachment by studying their behavior with their mother and an unfamiliar adult and their capacity to modulate affective expression. Zahn-Waxler et al. (1984) assessed the same group of seven index and seven control boys at the age of 30 months in their play with a same sex, same age, unfamiliar peer, and with their mother and the mother of the unfamiliar peer. They also collected observations from home visits and from mothers' rcports of the child's psychological problems for 1 year, beginning at 12 months. Davenport et al. (1984) administered Q-sorts concerning childrearing practices to the mothers of these index and comparison children when the children were 24 months old. 'These studies found that the children of depressed parents, as compared to the control group, seemed more fearful in free play and sadder at maternal separation and reunion at 12 months. At 15 months the index children seemed less fearful with maternal separation but more distressed during testing and at the approach of a stranger. At 18 months the children of depressed parents seemed to have less pleasure and less interest in testing and during maternal reunion, as well as more anger, displaced aggression, and distress in free play and in testing (Gaensbauer et al., 1984). Index children were more symptomatic, having more severe general symptoms and more depression-related symptoms. They also were generally rated as overexcited. They were less altruistic and sharing than controls, which declined even further during the course of assessment. The index children experienced heightened emotional arousal while observing the argument of two adult experimenters (Zahn-Waxler et al., 1984).

Children of depressed mothers were found to differ increasingly from control children as they grew older, beginning in the second year of life, which appears to be another crucial time for the emergence of untoward behavior in the child's interaction patterns, in addition to the interactional disturbances noted as emerging in the infant's first months of 
life. In the RLS study, children of depressed mothers did not differ from controls on various behavioral measures at 12 months, whereas by 30 months they were rated by their mothers as "less cooperative" with family or others, "more bizarre in behavior," "more depressed," and "more often engaged in imaginary play" (p. 97) than control children. In the NIMH study, the majority (5/7) of the children of depressed and normal mothers were rated as securely attached to their mothers during the first year, but by 18 months only 1 of the 7 index children was rated as securely attached, versus 4 of the 7 controls. Studies by Egeland and Sroufe (1981) and the NIMH group indicated a decline at 18 months in the security of attachment of children whose mothers were psychologically unavailable either because of economic or psychological factors. The percentage of securely attached infants of "psychologically unavailable" (but not necessarily depressed) mothers dropped from $57 \%$ at 12 months to $0 \%$ at 18 months.

Cicchetti and Aber (1986) argue that the depressed mother's combination of unavailability and overprotectiveness is paradoxical and that the mother's difficulties in managing her infant may appear in the first half of the second year when the infant becomes more active. Now that we are more aware that there are effects of maternal depression on the parent-child relationship even in the earliest months of life, we must consider the challenges faced by the mother and child in the second year of life as potentially exacerbating an already existing vulnerability. As the child begins to walk and talk, and struggles to separate from the mother, these activities stress the maternal caretaking capacities, and the basic attachment relationship may be transformed, if it has not been already, from one of security to one of insecurity. The mobility of the toddler also places greater demand on object constancy. While the child probably has developed recognition or libidinal constancy at 6-8 months (Fraiberg, 1969), he/she can confidently separate from the mother at around 16-18 months only if the capacity for object (or evocative) constancy has developed (Blatt, 1974). Also, while some depressed and psychologically unavailable mothers may be able to provide the basic care and feeding, and even nurturance, required by an infant, they may, because of their own disturbances in evocative constancy, be unable to tolerate the toddler's assertion for separation, independence, and autonomy, so that this time may constitute a second critical period at which disturbances in the relationship may develop (Blatt, 1991a).

The period of 16-18 months of age is particularly critical for the etiology of depression because many of the social, emotional, and cognitive competencies developing in late infancy and early toddlerhood are implicated in later depression. Included are the development of the autonomous self, the affect of shame, and especially the development of object constancy as mediated by the consolidation of an internal working model or representation of a secure attachment relationship. Also, during the second and third years of life a striving to meet adult standards emerges (Kagan, 1981). The beginnings of self-awareness (Kagan, 1981) and self-evaluation are expressed in feelings of shame and guilt, in developing self-confidence ("effectance motivation") (Harder, 1978), and the emergence of a sense of pride (Sroufe, 1983). Such indications of an emerging sense of self during the second and third years of life are consistent with Erikson's (1963) psychosocial formulations about the importance of issues of autonomy versus shame and initiative versus guilt in the second to fourth years of life, and with Helen Block Lewis's (1990) discussions of shame and guilt.

Lewis (1990) discusses shame as a "family of feelings: humiliation, mortification, feeling ridiculous, painful, self-consciousness, chagrin, shyness, and embarrassment . . . all hav[ing] in common that the self is helpless. 'Guilt', similarly refers to a family of feelings: fault, blame, responsibility, obligation” (p. 239). Lewis views shame as related to the entirety of the self, whereas guilt is about things done or undone for which the self is 
responsible. "In shame, the self has fallen short of its respected place not only in its own eyes, but also in the eyes of others. . . In guilt, the other is injured, or hurt, while the self . . . is able to repair it" (p. 241). The self is damaged in shame while the self is active in guilt in the efforts to make amends. Lewis (1990) reports that although securely attached infants eagcrly respond to their mothers' return after separation, they do so with a brief gaze aversion or a blank facial expression, which Lewis interprets as "a mixture of pleasure and some hint of shame" (p. 246). In discussing the responses of disorganized and avoidant insecurely attached infants, Lewis concludes that the avoidant infants may be expressing "the forerunner of a pattern of reaction that involves bypassing the shame of being rejected" and the expression of "humiliated fury." Lewis views avoidance as an early expression of shame as well as a shift of attention away from the attachment figure.

Guilt and shame are central issues in adult psychopathology, particularly introjective depression (Blatt, 1974), and these issues are also part of the struggle for independence, autonomy, self-definition, and self-worth that begin to emerge during the second year of life (see also Emde et al., 1986; Garmezy, 1987). There has been active debate about whether depression can exist as a distinct clinical entity in infancy or early childhood (Bemporad \& Wilson, 1978; Cicchetti \& Schneider-Rosen, 1984b; Garber, 1984; Rutter, 1986; see also reviews in Arieti \& Bemporad, 1978; Kashani et al., 1981), due in part to the tendency in the literature to define depression primarily in terms of self-critical and depreciating views of the self, and the understanding that the capacity for critical self-reflective evaluation appears later in development, and becomes stabilized as a psychological function sometime in early to mid-adolescence. However, other forms of guilt, such as around issues of separation and individuation from an insecure parent, or accptance of responsibility for negative events, seem to occur much earlier (Zahn-Waxler, Kochanska, Krupnick, \& McKnew, 1990). Children are much move vulnerable to experiences of object loss than to feelings of having failed to meet a set of internalized standards. Their cognitive limitations and egocentrism may lead them, when faced with abandonment or rejection, to feel that the loss is somehow their fault, and their dependence on the caretaker means that such feelings of responsibility would be intensely frightening to the child, and lead to further insecurity and expectations of further rejection.

Consistent with this conceptualization of different sources of guilt at different ages, Graham, Doubleday, and Guarino (1984) have distinguished between guilt for feeling responsible for uncontrollable events, which seems to be experienced more by younger children, and guilt due to feelings of responsibility for controllable events involving intentionality, which seems to be more characteristic of older children. (See also Freud [1930] for a distinction of guilt induced by the power of an external authority and a higher level of guilt derived from an inner authority.) Zahn-Waxler et al. (1990) point to the young child's egocentrism and lack of stable differentiation between self and other as making the child vulnerable to feeling responsible (i.e., guilty) for events that occur around them, and they also find very different patterns of guilt for normal children and for children of depressed mothers. The period of middle childhood seems to bc significant for the development of guilt and patterns of internalized responsibility in normal children, with guilt and emotional involvement increasing between 5 and 9 years of age, in association with concurrent increases in empathy and concern about interpersonal relationships. Children of depressed mothers, however, seem to develop symptoms of guilt much earlier, with differences between them and children of well mothers being apparent at age 5 (the youngest age sampled), "confirming the significance of yet an earlier period in development for internalization of responsibility" (p. 57). Gathering their data from both 
clinical interviews and semiprojective narratives about hypothetical events, Zahn-Waxler et el. found that the young children of depressed mothers show high levels, relative to normal children, of feelings of responsibility and emotional involvement. The older children of depressed mothers seemingly show arrested expressions of explicit guilt, but higher levels of distress and more frequent and more extreme "distortions" in their narratives than children of well mothers, suggesting that these children may actually have strong feelings of guilt, but struggle to defend against experiencing them directly. Distorted responses in the narrative were those containing "violent, unusual, unrealistic, or extreme elements . . . or indexes of vulnerability, hypersensitivity, or tension" (p. 54), such as "The mom's leaving home because the boy wouldn't eat her peas," or "The father was killed and cars kept running over the father, even the ambulance (and the mother and boy watched from the bedroom window)."

The authors conclude that the children of well and depressed mothers seem to be on "different pathways or trajectories" in their development of patterns of guilt, and they list several aspects of being raised by a depressed parent which could make a child more sensitive to issues of guilt and feelings of responsibility. Among these are a global home climate of distress and conflict, the child's proximity to the parent's own guilt and irritability, very high demands made on a young child, guilt and anxiety induction techniques used by the parent, judgmental attributions about the child, use of withdrawal of love as a type of discipline, and negative attributional styles modelled by the parent and learned by the rhild.

Peterson and Seligman (1984), in a cognitive-behavioral approach to depression based on learned helplessness theory, have focused on the tendency for guilt and depression to be associated with a pessimistic explanatory style in which the individual attributes bad events to enduring, global factors having to do with the individual rather than with external causes. Brewin and Furnham (1987) found that both dependency and selfcriticism, but especially self-criticism as measured by the DEQ, are significantly associated with a negative attributional style; while DEQ efficacy is significantly associated with a positive attributional style. Preliminary studies have shown convergence of mothers' and childrens' explanatory styles and depressive symptoms (Seligman et al., 1984), and gender differences between boys and girls and in the criticisms they receive from their teachers, in which girls appear to learn more pessimistic explanatory styles (Dweck \& Licht, 1980). Pessimistic explanatory style, in interaction with realistic aspects of a particular negative event, may produce an expectation that action will not control outcomes in the future, which in combination with the loss of self-esteem and guilt due to the blaming of the self is considered to be sufficient to cause (self-critical) depression. The method of transmission from parent or teacher to child could be explained through social learning theory (i.e., imitation, or through the child's internalization of the elder's expressed values). The parent's negative attributional style, however, may be only one component of a family environment which would generally be affected by depression and be harmful to the child's development of secure relationships and adaptive coping abilities.

\section{Adults' Retrospective Accounts of Childrearing Experiences and Depression}

A third approach to the study of the role of parent-child relationships in depression has been the investigation of individuals recollections of the patterns of their parents' caregiving behavior. Both psychoanalytic (e.g., Blatt, 1974) and cognitive behavioral theory (e.g., Beck, 1967; Becker, 1962) are consistent in their assumption that negative childrearing practices can be a precursor of depression in adults, in that these experiences can be internalized by the child and become elements of representations of self and of others, 
leading individuals to have negative cognitive schema about themselves, their environment, and the future (Beck, 1967; Beebe \& Lachmann, 1988; Blatt, 1974; Peterson \& Seligman, 1984).

Comparisons of depressed and nondepressed individuals in both nonclinical and clinical samples indicate that depressed individuals report more negative experiences with their parents (Blatt, Wein, Chevron, \& Quinlan, 1979; Burbach \& Bourdin, 1986). Most of these studies have relied on individuals' retrospective ratings and descriptions of their parents (e.g., Blatt, Wein, Chevron, \& Quinlan, 1979; Crook, Raskin, \& Eliot, 1981; Lamont, Fischoff, \& Gottlieb, 1976; Lamont \& Gottleib, 1975; Parker, 1981; Raskin, Boothe, Reatig, Schulterbrandt, \& Odle, 1971; Schaefer, 1965), while a few studies have used clinicians' evaluations of patients' early childhood experiences (e.g., Jacobson, Fasman, \& DiMascio, 1975). The use of retrospective reports and correlational data, however, leaves open a number of alternative possibilities beyond the conclusion that insufficient or distorted parenting creates a vulnerability to depression. For example, the depressed characteristics of the child possibly cause their parents to be less caring, or depression may cause individuals to view their parents more negatively. Descriptions of parents may reflect an individual's response set rather than the actual parental attitudes and behavior. Alternatively, it may be specific perceptions and representations of the parents rather than the parents' actual behaviors that leave individuals vulnerable to depression. Most studies of the etiology of psychopathology are speculative and exploratory, and therefore questions of validity and the direction of causality remain. The first step may be to identify how depressed subjects perceive their parents differently from nondepressed subjects, and then to establish to what degree these representations seem to reflect actual characteristics and behaviors of their parents, or of their relationships with their parents.

Several different methods have been used to study recollections of parental behavior, such as individuals' spontaneous descriptions of their parents (Blatt, Wein, Chevron, \& Quinlan, 1979) and the Parental Bonding Instrument (PBI), which assesses the dimensions of parental caring and overprotection (Parker, Tupling, \& Brown, 1979). Recent research (Blatt, Quinlan, \& Bers, 1991) found good convergent and discriminant validity between these two methods of assessing subjects' representations of their parents' behavior, as well as significant correlations of each measure with aspects of the Semantic Differential (Osgood, Suci, \& Tannenbaum, 1957). Thus, methods for obtaining retrospective accounts of caring experiences can potentially provide additional data for evaluating the relationship of depression to the nature of parent-child interactions and to the child's capacity to develop coherent internal working models (Main et al., 1985) or mental representations (Blatt, 1974) of secure care-giving relationships.

Blatt and his colleagues (1979) developed procedures for evaluating both the thematic content and cognitive organization of spontaneous descriptions of self and significant others. Individuals were asked, for example, to describe themselves and/or each of their parents. This procedure has been used with a wide range of subjects, in both clinical and nonclinical samples, to assess aspects of the mental representation of significant others, including one's parents, therapist, spousc, and so on. Scalcs were developed to rate 13 qualitative or thematic dimensions which, in a factor analysis, yielded three primary factors: nurturant, punitive, and ambitious (Blatt, Chevron, Quinlan, Schaffer, \& Wein, 1988; Blatt, Wein, Chevron, \& Quinlan, 1979; Quinlan, Blatt, Chevron, \& Wein, in press). In addition, based on an integration of concepts from developmental cognitive and psychoanalytic theory (Blatt, 1974), a procedure was developed to assess the level of cognitive organization (or conceptual level) of these mental representations. Conceptual level was assessed on a developmental continuum ranging from sensorimotor, to concrete 
perceptual images, to external and internal iconic representations, to complex, diverse, conceptual representations. ${ }^{\prime}$

Blatt (1974) applied these levels of conceptual development to formulations about anaclitic and introjective depression. In this conceptualization, anaclitic depression is characterized by sensurinotor-preuperational representation of care-giving figures, indicating these individuals' needs for direct, immediate, physical, need-gratifying contact with caregivers. The caregiver is not recognized as a separate and independent entity, and descriptions center on the direct value of the person for the subject. These clinically observed sensorimotor representations suggest that anaclitically depressed individuals have internalized representations of disturbed caring interactions, and therefore are vulnerable to depression provoked by current experiences of separation, abandonment, and neglect.

Clinical observations of introjectively depressed subjects' representations of their parents show them to be primarily at an external iconic level, focused on particular values and standards which are often stated in extremely harsh and negative terms. While the parent is perceived as a separate entity primarily in terms of functional activities and attributes, the harsh and critical parent seems to be experienced as an intrusive inner presence which is confused with and limits the development of an independent competent sense of self.

A series of studies explored the relationships between the two types of depression (dependent and self-critical) and recollections of childhood experiences, particularly the quality and cognitive organization with which adolescents and young adults describe their parents. As predicted, men and women with high dependency scores on the DEQ (anaclitic depression) had low conceptual levels in their description of their parents, while subjects with high DEQ self-criticism scores (introjective depression) demonstrated "intermediate" conceptual levels, and subjects scoring low on both DEQ factors of depression had the highest conceptual levels in their descriptions of their parents (Blatt, Wein, Chevron, \& Quinlan, 1979). Anaclitic and introjective depression were also both significantly related to the factors of nurturance, punitiveness, and ambition (Blatt, Wein, Chevron, \& Quinlan, 1979). Perceptions of the parents as lacking in nurturance and affection were more strongly related to depression than perceptions of parents as striving or judgmental. These results with normal subjects are consistent with carlicr studies using clinical samples (Jacobson et al., 1975; Lamont \& Gottlieb, 1975; Lamont et al., 1976; Raskin et al., 1971) and indicate that parental descriptions can be scored reliably, and that the content as well as formal (structural) aspects of parental representations significantly relate to types of depression.

Other studies, using other methods, have also examined how depressed subjects depict their parents. Lewinsohn and Rosenbaum (1987) found that acutely clinically depressed individuals described their parents as more emotionally rejecting than nondepressed controls, but not as using more negative controls (debasement, threats of punishment, and guilt manipulation) or as being more firm or lax in their discipline. Lewinsohn and Rosenbaum (1987) also found that emotional rejection was more central for depression in females than in males.

McCranie and Bass (1984) explored how relationships with controlling parents in childhood can produce dependent or self-critical depressive experiences. Controlling parents "view the child as an agent for satisfying their own needs for love and recognition rather than as an autonomous, self-willed entity. . . Methods of controlling the child are predominantly negative, exhibiting elements of strictness combined with inconsistent expressions of love and affection reflecting conditional acceptance" (p. 4). McCranie and Bass administered the DEQ the Strict Control, Conformity, and Achievement Control 
scales from the Parental Behavior Form (PBF), the Parental Inconsistency of Love scale (Schwarz \& Zuroff, 1979), and the Schwarz-Getter Interparental Influence scale to female nursing students. Dependent subjects described their mothers as the dominating, controlling parent, impeding the child's separation and individuation from her. Selfcritical subjccts, in contrast, describcd thcir parents as equally dominant, suggesting that they were no longer simply tied to the mother alone, and that self-criticism involved ambivalent feelings about both parents and especially about their parents' attempts to maintain control. Dependent women reported that their mothers emphasized conformity, while self-critical women reported parental emphasis on achievement and performance. The parents of self-critical, but not dependent, women were also reported to demonstrate love inconsistently. These findings are congruent with earlier reports (Jacobson et al., 1975; Lamont \& Gottlieb, 1975; Lamont et al., 1976; Parker, 1979a, 1979b; Raskin et al., 1971; Schwarz \& Zuroff, 1979), indicating "that depression proneness in general is influenced by parental childrearing practices that combine elements of rejection, inconsistent expression of affection, and strict control. Such behaviors could be expected to hinder the development of normal self-esteem in the child, resulting in an increased vulnerability to generalized feelings of helplessness and failure" (McCranie \& Bass, 1984, p. 7).

Focusing on possible childhood antecedents to self-critical depression, Johnson, Petzel, Dupont, and Romano (1982) found that subjects with elevated scores on the Beck Depression Inventory (a measure of self-critical rather than dependent depression) (Rlatt et al., 1982) thought their parents evaluated them more negatively than did nondepressed subjects. Depressed individuals also rated themselves as less active than controls and more discrepant from their parents' ideals for them on Osgood Semantic Differential dimensions of Evaluation and Activity, and by their fathers on Masculinity/Femininity. No differences were found between depressed and nondepressed subjects, however, in their perceptions of their parents' ideals for them. Such lack of a difference in the perception of parents' ideals suggests that depressed subjects do not have a generalized negative cognitive set, and that it is not the perception of extreme ideals and excessively high standards per se that relates to depression, but the different ways in which these ideals are presented that affect children. "It may be the case, then, that depressogenic parents do not set higher goals, they may just be more critical in cvaluating attempts to reach these goals" (Johnson et al., 1982; p. 61). These conclusions are consistent with reports discussed earlier (e.g., Cicchetti \& Aber, 1986; Davenport et al., 1984; Sameroff et al., 1982) that indicate that while depressed mothers do not differ from control mothers in their expressed attitudes about childrearing, they do differ markedly in their childrearing practices. Parents' views seem to dominate how depressed subjects feel about and evaluate themselves, in that the depressed individuals' evaluations of themselves corresponded with how they thought their parents perceived them. Thus, self-critically depressed subjects' negative views of themselves reflect the negative evaluation they have experienced from and continue to expect from their parents, and probably from others as well.

Some of the issues around the dynamic meanings of the different types of depression may be resolved by considering data gained from another appruach. Funseca (1987) studied college students selected for high scores on DEQ dependency and, using the subliminal activation method developed by Silverman (1966), compared the subliminal message "I am all alone" with the message "I have lost mommy" to study their differential effect in producing an increase in depressive affect expressed in verbalized memories, images, and fantasies. "I am all alone" was assumed to activate unconsciously the fear of not having one's needs met because of a total lack of available gratifying figures, whereas "I have lost mommy" was expected to stimulate unconsciously the fear of losing an 
important, specific, love object. The results indicated that fear of a total lack of supplies, as compared to losing a specific love object, stimulated significantly more depressive affect in anaclitically depressed individuals, and is therefore more central to the concept of anaclitic depression. These findings and interpretation are consistent with the fact that the central issue at a lower developmental level assumed to be associated with anaclitic depression is the gratifying action and not the object who provides the gratification. The object itself becomes important only sometime later in development.

Koufopoulos (1986) studied college-age women who scored high on DEQ self-criticism and, using the same subliminal activation method, explored the sources of guilt associated with introjective depression, such as guilt over separation/individuation as compared to guilt over anger, autonomy in general, and Oedipal desires. Using subliminal stimulation, Koufopoulos found that guilt over separation/individuation from mother significantly increased dysphoric affect in women vulnerable to introjective depression. Guilt over other issues (anger, autonomy in general, oedipal wishes) did not significantly increase depression. Thus, guilt specifically over separation/individuation emerged as the type of guilt most directly involved in introjective depression. These results are consistent with Cicchetti and Aber's (1986) identification of issues of separation/individuation as critical in the development of a vulnerability to later depression.

The data discussed so far about the relationship of certain parental characteristics to depression in offspring are, for the most part, both correlational and retrospective, making it hard to draw conclusions about the parents' actual characteristics. This problem of the validity of retrospective accounts of childrearing practices has been addressed to some extent by the work of Parker and his colleagues. Their studies indicate that retrospective reports can be both valid and reliable, and that the factors of parental lack of caring and psychological control are important antecedents of depression. Their studies have also ruled out several alternative, noncausal explanations.

Parker et al. (1979) developed the Parental Bonding Instrument (PBI), which assesses two basic factors of parent-child interaction-care and overprotection. The PBI, a 25-item questionnaire rated on 4-point Likert scales, has 12 items that address the dimension of caring/rejection, and 13 items that address the dimension of overprotection. Parker et al. (1979, p. 7) identify five possible types of parent-child bonds: "average" (defined statistically); high care-low overprotection ("optimal bonding"); low care-low overprotection ("absent or weak bonding"); high care-high overprotection ("affectionate constraint") and low care-high overprotection ("affectionless control"). The caring/rejection items evaluate the expression of "affection, emotional warmth, empathy, and closeness" as contrasted with themes of rejection such as "emotional coldness, indifference and neglect" (e.g., "Spoke to me with a warm and friendly voice" vs. "Did not help me as much as I needed"). The dimension of protection evaluates themes such as "control, overprotection, intrusion, excessive contact, infantilization and prevention of independent behavior... [as opposed to] allowance of independence and autonomy" (e.g., "Liked me to make my own decisions" vs. "Did not want me to grow up") (Parker et al., 1979 , p. 10). Subjects were asked to rate their experiences of their mother and father during their first 16 years. Alternate form and test-retest reliabilities were at acceptable levels and scores on the questionnaire were consistent with judges' ratings of these dimensions as assessed in personal interviews with the subjects. Subjects' reports of their parents' behaviors of caring and overprotection were also found to be independent of level of depression, as demonstrated by test-retest reliability after changes of 10 or more points on the Beck Depression Inventory $(r \geq .87$ ) (Parker, 1981). Scores on both subscales were also independent of age, sex, and social class.

Parker $(1979 \mathrm{a}, 1979 \mathrm{~b})$ found that reports of parental caring and overprotection corre- 
lated with dependency as measured by 12 selected items from the dependency scale of the DEQ (Blatt et al., 1976). Reports of paternal protection and maternal caring also correlated positively with hypochondriasis (Parker \& Lipscombe, 1980), indicating dependency is possibly related to hypochondriasis (see also Blatt et al., 1976). This association has implications for the possible role of overprotection in introjective and anaclitic depression. The influence of overprotection on depression would derive not just from its controlling, restricting aspects, evoking the anger, hopelessness, and self-criticism of introjective depression, but also from its anxiety-producing aspects, causing the child to feel generally vulnerable and afraid, as in anaclitic depression. In clinically depressed samples, the combination of low caring and high overprotection ("affectionless control") predicted the general level of depression, while in nonclinical samples, low maternal caring alone predicted the depression level. The correlation of overprotection with depression in clinical but not nonclinical samples is consistent with the characterization (Parker, 1982) of overprotection as having an especially negative influence on a child's development and as compounding the negative effect of a lack of parental caring. Furthermore, using general medical outpatients as a control group, Parker (1983) reports that female depressed patients tended to report affectionless control in their mothers (with a relative risk factor of 2.43), while male patients tended to report affectionless control in their fathers (relative risk, 3.66). "The relative risk of the patients assigning one or more parent to . . . [affectionless control] (with $67 \%$ of the patients and $37 \%$ of the controls so assigned) was 3.4 " (p. 958). In Parker's estimation, this is "not a trivial risk," but a risk comparable to the presence of affectionless control in other neurotic disorders, such as agoraphobia.

Perris et al. (1986) similarly found that of parents described by their children as demonstrating low "emotional wanth" and high "overprotection," $64 \%$ of the fathers and $76 \%$ of the mothers had children diagnosed as unipolar depressives. Gotlib, Mount, Cordy, and Whiffen (1988), in a study of postpartum depressed mothers, found that subjects whose depression remitted over 2-4 years reported higher parental care on the PBI than subjects whose depression did not remit. The remitted group had parental caring scores equivalent to a normal nondepressed control group, but the parental overprotection scores of the remitted as well as the nonremitted depressed group were significantly higher than the normal controls.

Another study (Parker, 1984) further explored the relationship of the risk factor of parental affectionless control to forms of pathology other than depression. The PBI was used to assess current rather than past parental attitudes and behaviors. The results suggested "that a parental style of 'affectionless control' may be irrelevant to certain psychiatric disorders (e.g., manic-depressive psychosis) [see also Matussek, Molitor, \& Seibt, 1985], but be an antecedent to, and a possible causal influence on other psychiatric disorders (e.g., neurosis), be a consequence of certain chronic disorders (e.g., asthma), and have a possible influence on the course of certain psychiatric disorders (e.g., schizophrenia)" (p. 81).

Support for the validity of the PBI is given by the high correlation between adult children's descriptions of their mothers and the mothers' descriptions of themselves on the PBI. Allowugh the mothers rated themselves as more caring and less overprotective than their children had rated them, the correlations between mother's self-description and the child's description of mother were highly significant. Maternal care and overprotection scores, whether rated by the mothers themselves or by their children, correlated significantly with depression scores of the subjects. Alternative hypotheses of pre-existing biological or temperamental predispositions as primary causes of depression are contraindicated by the findings that both depression and PBI scores were independent of maternal ratings of childhood dependency in their children, based on reports of childhood shyness, 
timidity, and levels of independence, and that nonclinical subjects adopted in infancy (Parker, 1982) revealed the same patterns as subjects raised by biological parents. In fact, the associations between PBI scores and depression were strongest for the subgroup of subjects who had been adopted within the first month after their birth.

Parker and Hadzi-Pavlovic (1984) found support for a causal influence of low care on depression in their observation that the level of affection in a woman's marriage appears to override the depressive effects of low parental care. Women reporting low parental care but high marital affection were less depressed than those reporting high parental care and low marital affection, and only slightly more depressed than those reporting high care from both sources. These findings are consistent with other studies which indicate that current uncaring family environments contribute to depression (Billings \& Moos, 1982; Coyne et al., 1987; Garrison, 1982; Wetzel, 1978; Wetzel \& Redmond, 1980). Parker and Hadzi-Pavlovic (1984) conclude that close affectional ties in adult life may modify the effects of parental deprivation. Subsequent research should investigate the relationship of level and type of depression to the capacity to experience close affectionate relationships. The capacity to establish meaningful interpersonal relationships may be an expression of diminished depression as well as an indication of a reduced vulnerability to depression.

Blatt et al. (1991) studied the relationships between Parker's dimensions of caring and protection and depression as assessed by the DEQ as well as by the Beck and Zung depression scales. In a nonclinical sample of young adult women, caring by mother and father had a significant $(p<.05)$ negative correlation with self-critical measures of depression (DEQ self-criticism and the Beck and Zung depression scales). Maternal and paternal overprotection in these women also correlated significantly with the DEQ self-criticism and the Beck and Zung scales, while mother's overprotection also correlated significantly with DEQ dependency. These relationships, however, were not as clear in young adult men. In men, mother's caring correlated negatively $(p<.05)$ only with the Beck; and father's caring correlated significantly only with the DEQ self-criticism, also in the negative direction. Maternal and paternal overprotection of males did not correlate significantly with any of the depression measures, except maternal overprotection was significantly $(p<.05)$ correlated with DEQ self-criticism. Thus, the relationship between Parker's dimensions of parental caring and protection and types of depression seems quite clear in young adult women, but these relationships are less consistent for young adult men. A longitudinal study of self-criticism by Koestner, Zuroff, and Powers (1991) found that children whose mothers had been rated as rejecting and restrictive by objective observers when the children were 5 years old were more likely to be self-critical at 12 years of age, and that in female subjects such self-criticism was still evident at 31 years. Self-critical 12-year-old boys, however, tended not to be still self-critical at 31 years, but reported greater experience of aggressive impulses, though not of aggressive actions.

Matussek et al. (1985), in differentiating various diagnostic groupings of depression, describe two kinds of childhood experiences that correspond roughly to the anaclitic/ introjective distinction. They found that of former inpatients who had been diagnosed as neurotically depressed, women felt that as children they received little attention from their mothers and little appreciation from their fathers, while men reported feeling distant from their fathers. Both men and women felt an "intrapsychic separation" from their mothers. They reported daydreaming and keeping secrets, a first sign of an "overcompensated, defiant autonomy" (Matussek \& Feil, 1983; Matussek et al., 1985, p. 19). Cicchetti and Aber (1986) similarly reported that young children of depressed mothers engaged in imaginary play more often than children of normal mothers. Matussek et al. (1985) found that neurotically depressed women felt rejected by their mothers; "their complaints 
evidence the existence of an inner concept, the imagining of a good object and a yearning for it. . . A Autonomy [in these patients] . . . is not genuine independence but an expression of a desperate struggle against feelings of need and dependence" (p. 19). Parents of neurotically depressed patients were described as often in conflict with each other, appearing as separate individuals, and thus facilitating their children's individuation. In contrast, unipolar endogenous depressed patients were strongly bonded to demanding mothers and saw their parents as coexisting in "absolute harmony." These unipolar endogenous depressed patients had a marked "deficiency of autonomy," manifested in a lack of opinions or interests and in overadaptiveness (Matussek et al., 1985, p. 19). Unipolar endogenous depression seems to be like anaclitic depression, in that the subjects are dealing with issues at a lower developmental level than the neurotically depressed patients, whose depression is more similar to introjective depression and who deal with issues at a higher developmental level.

One major drawback of retrospective studies is the possibility that the reporting subjects have unrealistically negative or positive cognitive sets which alter their perceptions of life events as well as their responses to questionnaires. Lewinsohn and Rosenbaum (1987) question whether reports of negative parental behavior by depressed individuals reflect basic early life experiences of individuals vulnerable to depression, or if they are a function of the current negative mood state of depressed individuals. They point out that a number of studies indicate that negative mood state, including depression, generally increases negative recall (Bower, 1981; Hammen, Marks, deMayo, \& Mayol, 1985; Isen, Shakler, Clark, \& Karp, 1978; Kuiper \& MacDonald, 1982; Teasdale, Taylor, \& Fogarty, 1980).

Contrary to the findings of Abrahams and Whitlock (1969), Gotlib et al. (1988), and Parker (1981) that negative reports were not influenced by current depressed mood, Lewinsohn and Rosenbaum (1987) found no significant difference in parental descriptions, using a modified version of the Children's Reports of Parental Behavior Inventory (CRPBI) (Schaefer, 1965), between normal controls and a group of subjects who were not currently depressed but had elevated scores $(\geq 18)$ on the Center for Epidemiological Studies - Depression (CES-D) as well as reports of prior depressive episodes on the Schedule for Affective Disorders and Schizophrenia (SADS) (Endicott \& Spitzer, 1978). Howcver, patients defincd as currently depressed according to Research Diagnostic Criteria (RDC) applied to the SADS semi-structured interview did recall their parents as more rejecting than did control subjects. These findings may suggest that feeling that one's parents have been emotionally rejecting may be intensitied by current negative mood states. Lewinsohn and Rosenbaum call for further investigation of the degree to which depressed individuals' memories of past events (such as parental behavior) are influenced by current depressive mood as well as prior early life experiences.

Several authors have noted the possibility of negative cognitive sets exaggerating subjects' criticisms of their parents (Bower, 1981; Gotlib et al., 1988; Parker, 1981; Perris et al., 1986). Such a pattern would be consistent with findings that introjectively depressed individuals are more separated and independent from their parents and consciously feel more ambivalent about their parents (Parker, 1980). But Johnson et al. (1982) argue that depressives do not have "a global and indiscriminant negative test-taking set" (p. 61) because they do not differ from nondepressives on rating what they perceive their parents expected of them. Brewin and his colleagues (Brewin, Firth-Cozens, Furnham, \& Andrews, in press) recently reported a significant relationship in women between the degree of self-criticism and reports of maternal lack of care and increased over-protection, even after controlling for the possible confounding effects of current mood state (e.g., level of happiness) and social desirability. Brewin et al. point out that these results are consistent 
with prior findings (e.g., McCranie \& Bass, 1984) and with a report by Gotlib et al. (1988) that postpartum depressed women report negative experiences with their parent on the PBI and that this level of negative report did not change when the depression remitted. In addition, several studies (e.g., Andrews \& Brewin, in press; Gold, 1986), using structurcd intcrvicws, found "cxtrcme ncgative self-attributions" (e.g., self-criticism) to be associated with repeated physical and sexual abuse, findings consistent with the frequent courtroom testimony of guilt and self-criticism in incest and abuse victims (Gelinas, 1983). Brewin et al. (in press) conclude that retrospective reports of parental behavior from self-critical individuals accurately reflect the nature of their experiences with their parents and is not the manifestation of current depressed mood.

There is some suggestion, however, that dependently depressed individuals may tend to minimize their dissatisfactions with their parents. The possibility of a positive cognitive response set in dependently depressed subjects could explain the unexpected findings in Parker and Lipscombe (1980), McCranie and Bass (1984), and Blatt et al. (1991), that a dependent depression is not strongly associated with reports of inconsistent love and/or a lack of parental care. Blatt (1974) and McCranie and Bass (1984) suggest that anaclitically depressed subjects may have difficulty expressing anger or disappointment for fear of losing people close to them, and may instead turn to denial as a defense against both the disappointment and the fear of loss - " . . individuals prone to experiences of dependency may be either less aware of or less willing to acknowledge parental rejection and inconsistent expression of affection" (McCranie \& Bass, 1984, p. 7).

An alternative explanation for the absence of a significant relationship between a lack of caring and a dependent depression could be that it is neglectful or overindulgent care rather than inconsistent care that leads to dependent depression, at least in women, while the ambivalence and guilt over anger toward the parents created by parental inconsistent care leads to self-critical depression. The inconclusive findings in dependent depression leave open the possibilities that anaclitic and introjective depression derive either from different parental behaviors or also from attitudes that differ only, or principally, in the time in the child's development at which the untoward parental behaviors were most intense and/or most influential.

Many of the studies examining the relationship of early childhood experiences to depression, however, do not differentiate between different types of depression; the measures of depression most frequently used are the Beck Depression Inventory and the CES-D, both of which assess primarily an introjective depression and issues of self-criticism and self-esteem rather than issues of dependency. Several recent studies using the DEQ (Blatt et al., 1976), the SAS (Beck et al., 1983), and the DAS (Weissman and Beck, 1978), and other procedures for differentiating dependency and self-criticism, however, have provided interesting additional data about the relationship of aspects of early experience with one's parents to vulnerability to different types of depression (e.g., Blatt, Wein, Chevron, \& Quinlan, 1979; Blatt, Quinlan, \& Bers, 1991; Brewin et al., in press; Lewinsohn \& Rosenbaum, 1987; McCranie \& Bass, 1984; Parker, 1981).

\section{CONCLUSIONS}

Investigators have sought to identify childhood antecedents of depression by studying children at risk because of being raised by depressed mothers, children who are insecurely attached to their parents, and adult retrospective accounts of childhood caretaking experiences with their parents. Evidence from these three types of investigations is consistent with the hypothesis that a primary antecedent of depression is an impairment of mental representations (Blatt, 1974) or of the internal working model (Main et al., 1985) of a 
care-giving relationship, deriving from disturbed interaction with the caregiver. Data from retrospective accounts suggest that experiences of parental lack of care, nurturance, or support, and excessive parental authority, control, criticism, and disapproval are associated with the later development of depression. Studies of attachment and children of depressed parents suggest that psychological unavailability contributes to interactional and attachment difficulties, which are expressed in impaired or distorted representations of caring relationships. These disrupted mental representations or internal working models of caring relationships may vary according to the parenting style experienced by the child, and become consolidated in patterns of behavior. Different types of insecure attachment lead to different behavior patterns and these probably relate to whether the parents are experienced as uncaring and neglectful or as overcontrolling and intrusive. Tentative parallels can be drawn between types of attachment behavior (insecureambivalent and insecure-avoidant), types of parenting (enmeshed and dismissing) (Main et al., 1985), and two kinds of depression: dependent and self-critical. While the correspondences are still unclear between affectionless control as described by Parker et al. (1979) and Parker (1983), enmeshment and dismissiveness as described by Main et al. (1985), and the irritability, negativity, and psychological unavailability described by researchers of depressed mothers and their children (Cohn et al., 1986; Davenport et al., 1984; Egeland \& Sroufe, 1981), elements of lack of responsiveness and psychical control are present in each, especially if one considers enmeshment as the use of caring as a means of control.

One avenue through which disturbed mother-child interactions may lead to later depression in the child is the mother's failure to help the infant in the regulation of affect. Tronick and Gianino (1986) have described a "Mutual Regulation Model," in which the infant uses self-regulatory behaviors to control its level of stimulation, and also uses the mother to help reduce high levels of stimulation. When mother fails to respond to the infant's signals, the infant may become overwhelmed and disorganized, experience negative affect, and over time develop a conception of the self as ineffective and the mother as unreliable (Schaffer \& Blatt, 1990). Beebe and Lachmann (1988) point out that the mother can be engaged with the infant and responding contingently in a temporal sense, but that regulation of the infant's affect, arousal, and attention will still fail if mother and infant arc "misattuncd" (i.c., the mother may increase arousal while the infant necds to decrease, or fail to match the infant's affective valence). Moment-by-moment studies of mother-infant interaction have shown that normal dyads move to meet each other in a contingent way on dimensions of affect, level of arousal, and attention, in a continuous cycle of interactive error and repair (Field et al., 1990; Tronick \& Gianino, 1986), and that the failure of such matching, as in studies of simulated depression (Cohn \& Tronick, 1983; Field et al., 1988), leads to negative responses (protest, diverting of gaze) in the child. The level of a depressed caregiver's negative affect experienced by the child is also increased by the infant's tendency to match the mother's negativity and the tendency for a high proportion of the dyad's matched states to be negative (e.g., intrusive/protest, disengaged/look away) (Field et al., 1990).

Continuity between very early disturbed interaction patterns and later altachnent has been found in several studies (see Beebe \& Lachmann, 1988). Both insecure-avoidant and insecure-ambivalent children display behaviors suggestive of nonideal patterns of affect regulation, the first expressing little or no affect, punctuated by rare outbursts of anger (Main, 1981), and the others being overcome by their distress and unable to be comforted by the caregiver. Disorganized-disoriented children demonstrate unusual regulation of emotion in their dazed and depressed-appearing aspects, and in their disjointed alternations between approach and avoidance. 
While these patterns each represent maladaptive forms of regulation or expression of emotion, they may also be considered adaptive in the context of the relationship with the caregiver, and the child or adult in a stressful situation later in life may return to these patterns, not only because it is what he or she knows best, but also because these behaviors represent some kind of promisc or chance for rclative comfort or sccurity. On a rclated note, Zelnick and Buchholz (1990) follow Freud (1900) and other psychoanalytic thinkers, such as Blatt (1974), Stolorow (1978), and Pine (1974), in postulating that mental representations themselves may be comforting or self-regulating in their idealizing, wishfulfilling functions. "Imagine the functional advantages to a child of an internal representation which can be shaped to represent both wish and reality" (Zelnick \& Buchholz, p. 40).

In addition to the usual conceptualization of depression as a disturbance in affect regulation, increasing attention has been paid to the cognitive and behavioral components of adult depression. Cicchetti and Sroufe (1978) have discussed the importance of studying the changing organization of cognition, behavior, and affect. Blatt (1974), for example, based on an integration of aspects of cognitive developmental theory (e.g., Piaget \& Werner) and concepts of developmental psychoanalytic theory, describes these changing levels of organization as ranging from a sensorimotor-preoperational level to an integrative conceptual level. Higgins (1989), based on concepts of social cognition, proposes a model of cognitive organization ranging over five developmental levels from an early sensorimotor to a "later vectorial" developmental level. Blatt's (1974) formulations of impairments in the developmental level of mental representation of caregivers in depression, Higgins' (1989) formulation of the role of mental representation of caretaker interactions in affect regulation and sclf-cvaluation, and Main's elaboration of Bowlby's concept of internal working models as guides to cognition (attention,memory) and behavior (reunion and coping responses), as well as affect (sadness, anger) in attachment-related situations, can serve as unifying constructs which permit the study of the organization of behavior and affect across various developmental stages (Zelnick \& Buchholz, 1990).

The emphasis on the development of a consolidated and consistent mental representation or internal working model of attachment relationships as an important dimension of normal development is consistent with the recent emphasis in cognitive theory on the importance of schemas, prototypes, and scripts in development. Psychological theory has moved beyond the hedonic models of associative learning and the drive-defense resolutions of classic psychoanalytic theory, to an understanding of human behavior as being determined by the organization of meaning and memory structures that are expressed in the form of plans (e.g., Miller, Galanter, \& Pribram, 1960), expectancies (Feather, 1966), schemes (e.g., Neisser, 1967, 1976; Piaget, 1962/1945; Werner, 1948), and scripts (e.g., Shank \& Abelson, 1977). While individuals may use different schema and memory structures (Bartlett, 1932; Fiske \& Linville, 1980; Hastie, 1981; Piaget, 1954; Taylor \& Crocker, 1987; Werner, 1948) in different types of situations, individuals have predominant schemes or preferred modes of organizing experiences and constructing meaning which determine their perceptions and understanding of physical and social reality (Blatt, 1971; Bruncr, 1986; Gardner, 1984; Goodman, 1984). These cognitive schema of the self and others and of the actual and potential nature of interpersonal interactions govern and regulate all human behavior including social interaction (Beebe \& Lachmann, 1988; Blatt, 1991a).

Beebe and Lachmann (1988) and Stern (1985) have described the normal infant's developing sense of the self as capable, coherent and positive as deriving from consistent interactions with a responsive, attuned mother. Zelnick and Buchholz (1990) also cite Sandler, Holder, and Meers' (1963) position that a child's model of "ideal self" may 
correspond to idealized representations of the object, and that "when it does, it allows the child the gratification that he or she has complied with parental injunctions and will be loved for his or her compliance, as well as allowing the self-representation to be admired as the object is admired" (Zelnick \& Buchholz, p. 38). Profound untoward experiences carly in the life situation can lcad to distorted, unrealistic, and disruptive schema of the self and others because they derive from negative interactions - from relationships that are undependable, overindulgent, chaotic, or unregulated, and that have been internalized, possibly as self- as well as object-representations. In this view, a child who can preserve some aspects of positive dimensions of the otherwise disruptive caregiver might show some resilience to future pathology.

Higgins (1989) discusses how differences in caretaker-child interactions influence the development of self-regulation and self-evaluation. Higgins notes that there are basically two types of positive psychological caretaking situations: (a) the presence of positive outcomes and (b) the absence of negative outcomes. Some parents attempt to minimize the likelihood that their child will experience a negative outcome while other parents try to maximize their child's positive outcomes. There are also two basic types of negative psychological caretaking situations: (a) the absence of positive outcomes and (b) the presence of negative outcomes. A punitive/critical disciplinary style is more likely to be associated with children experiencing the absence of positive outcomes. Higgins (1987) on the basis of self-discrepancy theory predicts that children experiencing self-other interactions with negative outcomes would be more vulnerable to agitation-related emotions (e.g., fear, worry, edginess), whereas children experiencing self-other interactions involving the absence of positive outcomes would be more vulnerable to dejection-related emotions (e.g., sadness, discouragement).

The four types of caretaker-child interactions (positive outcomes, absence of negative outcomes, absence of positive outcomes, presence of negative outcomes) is somewhat similar to Parker's distinctions, in that Higgins identifies four caring modes which he labels as "neglectful," "abusive," "spoiling," and "overprotective." The two "disciplinary" modes (neglectful and abusive) are likely to contribute directly to a vulnerability to the self-system, consistent with the findings that "strict/demanding" and "cold" parenting styles are reported to relate to levels of depression in undergraduates (Bohrnstedt \& Fisher, 1986). Higgins (1989) speculates that extreme levels of other modes could be associated with other types of emotional problems.

Higgins (1989) notes that the characteristics of child-caretaker interaction is only one source of socialization in the development of the child's self-regulatory and self-evaluative processes, and other factors have to be considered such as family size, sex composition and age of siblings, number and sex of caretakers, and so forth. Also, the child's changing capacities for mental representations and different life phases interact with caretakerchild relationships to influence the development of self-regulation and self-evaluation, as well as emotional predispositions.

Peterson and Seligman (1984), from a cognitive perspective, have focused on the tendency for depression to be associated with a pessimistic explanatory style in which the individual attributes bad events to enduring, global, and intcrnal factors, producing an expectation of being unable to influence events which will happen to one in the future. The individual suffers diminished self-esteem and symptoms of helplessness, such as passivity, cognitive and neurochemical deficits, sadness, anxiety and hostility, lowered appetite, and heightened susceptibility to disease. Pessimistic explanatory style and its apparent accompanying vulnerability to a hopeless, self-critical depression also seems to be transmitted from mother to child (Seligman et al., 1984). 
An important step in understanding childhood antecedents to depression is the identification of critical periods at which certain kinds of parenting styles may be the most influential. In the research reviewed here, two critical periods seem to be identified. The first, while still quite ambiguous and requiring a great deal of further longitudinal research, seems to be the first 6 months of life. Cross-sectional studies indicate a shift in infants of chronically depressed, intrusive mothers from high levels of protest at 2 months to high levels of disengagement, or looking away, at 6 months, which Cohn et al. (1990) interpret as an "attenuated" interest or engagement in interpersonal interaction. By age 6 months, infants of chronically depressed mothers may have formed an expectation of not being responded to, and, lacking regulatory help from the mother, have turned to self-soothing behaviors and away from more interactive involvement. These speculations must be regarded as tentative, since they are drawn from results of different studies with different samples (although both samples were made up of low SES, high-risk dyads). The implications of such a critical period, however, could be considerable for the ability of the child to respond after 6 months to remission of the mother's pathology, and for goals of interventions before 6 months, especially given Field et al.'s (1990) assertion that infants are no longer depressed at 6 months if their mothers are also no longer depressed.

Another critical transition period appears to be the second year of life, the outcome of which may strongly influence the potential vulnerability to future depression (Blatt, 1974; Blatt \& Shichman, 1983; Cicchetti \& Aber, 1986). Issues of control and security become heightened at this time for both the mother and the child, as the toddler gains mobility and seeks both autonomy and a safe place to return. The experience of controlling, unresponsive parents at a time when the child is beginning to establish a sense of selfworth and identity could create a tone of anger and resentment in interpersonal relationships, and a depreciated sense of the self related to feelings of guilt, shame, and inadequacy. Children raised by depressed and unresponsive mothers may be more vulnerable in separation because they have not developed a consolidated and essentially positive sense of the mother, or of the self in interaction with the mother. The depressed mother's caretaking patterns also create experiences of the self as helpless and lonely, rather than allowing the child to experience the joy of independence that comes with separation (Schaffer \& Blatt, 1990).

Yet another influence on the child's potential future depression is the gender of the psychologically unavailable or affectionless controlling parent and the child. While most of the studies reported here have pointed to the mother as the more influential parent (Main et al., 1985; Parker, 1979, 1982, 1983; Parker \& Hadzi-Pavlovic, 1984), this pattern has not been wholly consistent, with some studies finding paternal caring (Parker \& Lipscombe, 1980), the same-sex parent (Matussek et al., 1985), or both parents (Blatt et al., 1991; Johnson et al., 1982; McCranie \& Bass, 1984) to be primary, and others, such as the studies of depressed mothers, not examining the father's role at all. The model of psychological development proposed by Blatt and Shichman (1983) suggests that girls' developmental demand for a shift in the attachment of affection from mother to father in early childhood and boys' developmental demand for a shift in identification from mother to father in early childhood could account for the differential tendency for females to become more often depressed around interpersonal issues (i.e., dependency) and for males to become more often depressed around issues of self-definition (i.e., self-criticism). This model also stresses the importance of the attitudes and behaviors of the same-sex parent for depression in offspring, as well as suggesting that the nature and timing of the mother's and father's untoward behavior could contribute differentially to the child's 
development and determine the degree and nature of subsequent vulnerability to depression-whether it is primarily focused around issues of dependency, or self-worth and self-criticism, or both.

These different sources for disruption of the parent-child relationship are consistent with the formulations of Blatt (1974; Blatt et al., 1976, 1982), Arieti and Bemporad (1980), Bowlby (1980), and Beck (1983) of two types of depression, one focused on a loss of interpersonal relatedness (i.e., dependency) and corresponding to a level of sensorimotor functioning, and the other centering on issues of self-worth and self-definition that evolve during the separation/individuation phase. The investigation of interactional sources of dependent and self-critical depressions allows us to conceptualize two types of object relations, which both have depressive reactions to certain kinds of events that resonate with specific interpersonal fears and dangers. Introjectively depressed patients berate, criticize, and attack themselves with intense feelings of guilt, shame, and worthlessness. They are driven by the danger of loss of parental approval for failing to meet stern and harsh parental standards and expectations. The child's struggles toward separation, individuation, and self-definition are thwarted by the internalized judgments of one or both parents and their tendencies to be intrusive and controlling. The child experiences parental love as conditional and as contingent upon meeting very strict parental standards, and becomes depressed in response to perceived failure or criticism. The child's constant self-censure is also a repetition of the child's relationship with his/her parents and in this way may be an identification with the parents which enables the child to maintain contact with them (Blatt, 1974). The relationship with both parents is probably at issue in this type of depression.

In anaclitic depression, fear of losing the object's care and nurturance is the primary concern. The mothering figure was generally unavailable or used her love and care to control the child, either by withdrawing love or perhaps through overindulgence. The dependency and insecurity engendered by the mother's unavailability (or excessive availability) makes it difficult for the child to develop a stable representation of the mother as caring, and this pattern is repeated in subsequent relationships. Without a stable and consolidated internal mental model of a caring mother, the child cannot maintain a sense of continuity with the mother in her absence, nor believe and trust that the pleasure of being loved and cared for can continue beyond the immediatc moment. Dependent individuals need constant reaffirmation about the availability of care, desperately seek attention and nurturance, and become depressed in reaction to separations or perceived abandonment. They have felt the love of the mother to be contingent upon being obedient and conforming, feel helpless about ever feeling secure in relationships, and are likely to deny anger and to be overwhelmed by unfulfilled longing to be cared for (Blatt, 1974).

Many research issues are raised by the studies reviewed in this paper; some are pragmatic and others are more theoretical. Subsequent studies need to standardize research techniques and to apply them to diverse samples (SES, race, age, marital status, birth order) and to different diagnostic groups (e.g., types of depression), using well-established measures of clinical depression (RDC, SADS, BDI) as well as measures that distinguish between types of depressive experiences (e.g., DEQ SAS, DAS). It is also important to find ways of systematically and reliably assessing a wide variety of early life experiences, including the experience of parental behavior, such as affectionless control and psychological unavailability, and to integrate research procedures and findings from the laboratory, the clinic, and home observations.

Research also needs to establish the reliability and validity of retrospective reports, recognizing that these reports provide another important perspective on the parent-child interaction (i.e., how it was experienced by the child) and these experiences should be 
coordinated with direct observations of parental behavior. We need to find ways of identifying both positive and negative reporting biases and to understand them not only as dimensions that affect research designs, but also as biases that relate to dynamic issues within the individual.

Longitudinal research should include an asscssment of other potential factors related to depression, including familial predispositions, especially if the depressed relative is not the source of interactional difficulties, and possible protective or moderator variables such as a good relationship with the other parent or other relatives as well as support systems that may be available outside the home. The entire area of investigation into the role of parent-child interaction in the etiology of depression has demonstrated the vital importance of longitudinal research designs in the study of personality development and of psychopathology. Emerging research using causal modeling has also begun to establish the reciprocal influence of characteristics of both mother and child and the importance of including both maternal and child variables in studies of the etiology of depression (Hammen, Burge, \& Stansbury, 1990).

We need to study less severe forms and earlier phases of psychological disorders and to study nonclinical samples of children longitudinally, from very early in life. This will enable us to appreciate the multiplicity of forces (biological, psychological, and social) that impinge upon the child in the complex series of interactions that lead to different modes of adaptation. Some of these modes of adaptation are constructive and others distorted, some even leading to the formation of serious psychopathological states. Specific developmental patterns and processes need to be identified at different phases of the life cycle in order to examine their roles in the development of psychopathology. Prototypes and precursors of pathology related to parent-child interaction may be identified in early forms of maladaptive behavior patterns or impaired cognitive structures (Bowlby, 1969; Blatt, 1974; Blatt \& Shichman, 1983; Cicchetti \& Aber, 1986; Cicchetti \& Schneider-Rosen, 1984b). In considering developmental deviations, however, it is important to avoid formulations that focus on limited and specific pathogenic events, such as a single traumatic experience. It is necessary to consider the interaction between particular individual characteristics and environmental responses at a given time and over various developmental periods (Sameroff \& Chandler, 1975), and the balance between risk factors and compensatory buffers (Cicchetti \& Aber, 1986). A depressive episode occurs when a multiplicity of interacting factors overwhelm the individual's adaptive capacities (Cicchetti \& Aber, 1986). The organization of behavior into particular patterns of insecure attachment as identified by Ainsworth et al. (1978) and Main et al. (1985) could represent a vulnerability factor for depression, especially when these patterns of insecure attachment interact with untoward contemporary life events which are congruent with the basic issues underlying the insecure attachment (Blatt \& Zuroff, in press).

A comprehensive developmental model of the etiology of depression must consider the multifaceted ways in which constitutional, organismic (Werner, 1948), and environmental factors transact to affect development and to create vulnerabilities to depression, such as impairments in the cognitive structures based on disturbed environmental experiences. Vulnerability factors may include the relatively enduring characteristics of the child, the parents as individuals, the family, and the social environment, as well as stressful life events, such as the death of a parent during the subject's childhood. Beyond the traditional formulations of the diathesis-stress model, one must consider the hierarchies of factors that create depression. Certain temperamental or biological qualities may predispose an individual child to insecure attachment through the impact that these temperamental dimensions have on the parents and their capacity to care adequately for their child. It is not these biological or temperamental qualities of the child and/or the parent per se that 
create the insecure attachment and the vulnerability to depression, but rather a lack of congruence of these biological capacities and tendencies between infant and parent has potential to disrupt and distort the caring relationship that influences the child's capacity for attachment and the development of adequate levels of mental representations or working modcls of caring relationships. Onc important disruptivc factor in development may be the relative inability of parent and child to find constructive ways of resolving major temperamental differences, which disrupts the child's development of secure attachment and the establishment of effective levels of mental representation of the caring relationship. Despite the individual characteristics of parent and child, the quality of the emotional attachments and the consequent development of mental representations of caring relationships appear to be central to subsequent emotional and cognitive development (Blatt \& Wild, 1976).

The study of the antecedents and precursors of depression will proceed more rapidly and effectively if depression is viewed as more than just a clinical disorder, but as an affect state that varies from normality to pathology, from mild, transient, appropriate dysphoric reactions to untoward life events, to severe, disabling, persistent and intense dysphoric reactions that have little justification in current life circumstances (Blatt, 1974). In addition to studying the precursors of clinical depression, we need to identify the specific cognitive, emotional, interpersonal, linguistic, physiological, and other developmental processes that lead to loneliness, sadness, and feelings of worthlessness and selfcriticism in children and adolescents. We also need to identify the multiple ways in which feelings of depression are expressed in children, including dysphoric mood, suicidal thoughts, sleep disturbances and anhedonia, as well as the multiple forms of defense that children, especially adolescents, often use against depression, such as denial, mania, and displacement in various types of enactments (Blatt, 1991b). The problems are intriguing and important, with possible implications for both treatment and prevention. There are, of course, inherent difficulties in each type of research reviewed here, but the convergence of findings from multiple perspectives - from different theoretical orientations and different types of research designs-has enabled us to clarify some of the complexities of parent-child interactions and their role in child development. The continued longitudinal study of parent-child interactions and the understanding of depressed individuals' perceptions of their current as well as their past life experiences will provide us with further insight into some of the factors contributing to the development of depression in childhood, adolescence, and adulthood.

Acknowledgement - We are indebted to Dr. Beatrice Beebe for her helpful comments and criticisms.

\section{ENDNOTE}

(a) Sensorimotor-Preoperational. People are described primarily by the gratification or frustration they provide, causing the subject either pleasure or pain. The description has a personal, subjective focus, and the person is not cxpcrienced or defincd as a separate and independent entity. The description centers on the direct value the person has for the subject.

(b) Concrete-Perceptual. A person is described as a separate entity, but the description is primarily concrete, global, and literal, often characterized by physical attributes.

(c) External-Iconic. People are experienced as separate entities in terms of their functional activities and attributes, but in contrast to Sensorimotor-Preoperational, the activities are not directly need-gratifying for the subject. 
(d) Internal-Iconic. People are described by their attributes and part properties, not in terms of what they do but rather what they think, feel, value, and so forth. The description concerns more internal dimensions. Adjectives that are behavioral descriptions, such as happy, playful, and gregarious, are between external and internal iconic, with internal iconic being reserved for descriptions that convey the internal state of the person in such a way that the reader can empathize with the person's experiences of reality.

Neither the external nor the internal iconic descriptions convey a complexity of actions, feelings, values, or a development over time, or any integration of apparent contradictions. Iconic traits may have an implicit reference to the subject, particularly in descriptions given by children and adolescents, but they are iconic traits if a person is described as separate and unique from the subject.

(e) Conceptual. The person is described in a way that integrates all of the prior levels. The total description indicates that the person is understood and experienced on a wide range of levels. There is an appreciation of internal dimensions in their own right as well as in contrast to the external. Also, there may be a time line in which change and variation are appreciated. There are a variety of dimensions that integrate and resolve apparent contradictions. Thus, there may be a sense of disjunctiveness in which the manifest, literal, and concrete appear in contradiction to more internal dimensions. But the apparent contradiction is resolved in an integrated, complex synthesis. At this level there can be comments about the need-gratifying attributes, or physical and functional characteristics of the person, but they are part of a cohesive and integrated description.

\section{REFERENCES}

Abrahams, M. J., \& Whitlock, F. A. (1969). Childhood experience and depression. Journal of Psychiatry, 115, 883-888.

Abramson, L. Y., \& Sackheim, H. A. (1977). A paradox in depression: Uncontrollability and self blame. Psychological Bulletin, 84, 838-851.

Abramson, L. Y., Seligman, M. E., \& Teasdale, J. D. (1978). Learned helplessness in humans: Critique and reformulation. Journal of Abnormal Psychology, 87, 49, 74.

Ainsworth, M. D. S. (1969). Object relations, dependency, and attachment: A theoretical review of the mother-infant relationship. Child Development, 40, 969-1025.

Ainsworth, M. D. S. (1982). Attachment: Retrospect and prospect. In C. M. Parkes \& J. Stevenson-Hinde (Eds.), The place of attachment in human behavior (pp. 3-30). New York: Basic Books.

Ainsworth, M. D. S., Bell, S. M., \& Stayton, D. J. (1971). Individual differences in strange-situation behavior of one-year olds. In H. R. Schaffer (Ed.), The origins of human social relations (pp. 17-57). London: Academic Press.

Ainsworth, M. D. S., Blehar, M. E., Waters, E., \& Wall, S. (1978). Patterns of attachment: A psychological study of the stranger situation. Hillsdale, NJ: Lawrence Erlbaum Associates.

American Psychiatric Association (1987). Diagnostic and statistical manual of mental disorders-DSM-III (3rd ed. rev.). Washington, DC: Author.

Andrews, B., \& Brewin, C. R. (in press). Attributions of blame for marital violence: A study of antecedents and consequences. Journal of Marriage and the Family.

Angyal, A. (1951). In E. Hanfmann \& R. M. Jones (Eds.), Neuroses and treatment: A holistic theory. New York: Wiley.

Arend, R., Gove, F. L., \& Sroufe, L. A. (1979). Continuity of individual adaptation from infancy to kindergarten: A predictive study of ego resiliency and curiosity in pre-schoolers. Child Development, 50, 950-959.

Arieti, S., \& Bemporad, J. R. (1978). Severe and mild depression: The therapeutic approach. New York: Basic Books.

Arieti, S., \& Bemporad, J. R. (1980). The psychological organization of depression. American Journal of Psychiatry, 137, 1360-1365.

Bakan, D. (1966). The duality of human existence: An essay on psychology and religion. Chicago: Rand McNally.

Bartlett, F. C. (1932). Remembering. Cambridge, UK: Cambridge University Press.

Bates, J. E., Maslin, C. A., \& Frankel, K. A. (1985). Attachment security, mother-child interaction and temperament as predictors of behavior-problem ratings at age three years. Monographs of the Society for Research in Child Development, 50, 167-193. 
Beardslee, W. R., Bemporad, J., Keller, M. B., \& Klerman, G. L. (1983). Children of parents with major affective disorder: A review. The American Joumal of Psychiatry, 140, 825-832.

Beardslee, W. R., \& Podorefsky, D. (1988). Resilient adolescents whose parents have serious affective disorders: Importance of self-understanding and relationships. American Joumal of Psychiatry, 145, 63-69.

Beck, A. T. (1967). Depression: Clinical, experimental and theoretical aspects. New York: Harper and Row.

Beck, A. T. (1903). Cognitive therapy of depiession: New perspectives. In P. J. Clayton \& J. E. Barrett (Eds.), Treatment of depression: Old controversies and new approaches (pp. 265-290). New York: Raven.

Beck, A. T., Epstein, N., Harrison, R., \& Emery, G. (1983). Development of the sociotropy-autonomy scale: A measure of personality factors in psychopatholngy. Unpublished manuscript, University of Pennsylvania, Philadel. phia, PA.

Beck, S., \& Rosenberg, R. (1986). Frequency, quality, and impact of life events in self-rated depressed, behavioral-problem and normal children. Journal of Consuling and Clinical Psychology, 54, 863-864.

Becker, E. (1962). Toward a comprehensive theory of depression: A cross disciplinary appraisal of objects, games and meaning. Joumal of Nervous and Mental Disease, 135, 26-33.

Beebe, B., \& Lachmann, F. M. (1988). The contribution of mother-infant mutual influence to the origins of self and object representations. Psychoanalytic Psychology, 5, 305-337.

Bemporad, J. R. (1978). Psychodynamics of depression and suicide in children and adolescents. In S. Arieti \& J. R. Bemporad (Eds.), Severe and mild depression (pp. 185-210). New York: Basic Books.

Bemporad, J. R., \& Wilson, A. (1978). A developmental approach to depression in childhood and adolescence. Journal of the American Academy of Psychoanalysis, 6, 321-352.

Billings, A. G., \& Moos, R. H. (1982). Social support and functioning among community and clinical groups: A panel model. Journal of Behavioral Medicine, 5, 295-311

Blaney, P. H., \& Kutcher, G. S. (1991). Measures of depressive dimensions: Are they interchangeable? Joutnal of Personality Assessment, 56, 502-512

Blatt, S. J. (1974). Levels of object representation in anaclitic and introjective depression. The Psychoanatytic Study of the Child, 24, 107-157.

Blatt, S. J. (1990a). Interpersonal relatedness and self-definition: Two personality configurations and their implications for psychopathology and psychotherapy. In J. Singer (Ed.), Repression and dissociation: Implications for personality theory, psychopathology $\Theta^{2}$ health (pp. 299-335). Chicago: University of Chicago Press.

Blatt, S. J. (1990b). The Rorschach: A test of perception or an evaluation of representation. Journal of Personality Assessment, 54, 236-251.

Blatt, S. J. (1991a). A cognitive morphology of psychopathology. Journal of Nervous and Mental Disease, 179, $449-458$

Blatt, S. J. (1991b). Depression and destructive risk-taking behavior in adolescence. In L. P. Lipsitt \& L. L. Mitnick (Eds.), Self-regulatory behatior and risk-taking: Causes and consequences (pp. 985-309). Norwnod, NJ: Ablex.

Blatt, S. J., \& Blass, R. (1990). Attachment and separateness: A dialectic model of the products and processes of psychological development. The Psychoanalytic Siudy of the Child, 45, 107-127.

Blatt, S. J., Chevron, E. S., Quinlan, D. M., Schaffer, C. E., \& Wein, S. (1988). The assessment of qualitative and structural dimensions of object representations. Unpublished manuscript, Yale University, New Haven, CT.

Blatt, S. J., D'Aflitti, J. P., \& Quinlan, D. M. (1976). Experiences of depression in normal young adults. Journal of Abnormal Psychology, 85, 383-389.

Blatt, S. J., D'Aflitti, J. P., \& Quinlan, D. M. (1979). Depressize Experiences Questionnaire. Unpublished manual, Yale University, New Haven, CT.

Blatt, S. J., \& Lerner, H. (1983). Investigations on the psychoanalytic theory of object relations and object representations. In J. Masling (Ed.), Empirical studies of psychoanalytic theories (Vol. 1, pp. 189-249). Hillsdale, NJ: The Analytic Press.

Blatt, S. J. \& Maroudas, C. (in press). Convergences among psychodynamic and cognitive-behavioral theories of depression. Psychoaralytic Psychology.

Blatt, S. J., Quinlan, D. M., \& Bers, S. (1991). Depression and the tepresentation of parental behavior in normal young adults. Manuscript submitted for publication.

Blatt, S. J., Quinlan, D. M., Chevron, E. S., McDonald, C., \& Zuroff, D. (1982). Dependency and self-criticism: Psychological dimensions of depression. Journal of Consulting and Clinical Psychology, 150, 113124.

Blatt, S. J., \& Shichman, S. (1983). Two primary configurations of psychopathology, Psychoanalysis and Contemporary Thought, 6, 187-254.

Blatt, S. J., Wein, S. J., Chevron, E. S., \& Quinlan, D. M. (1979). Parcntal representation and depression in normal young adults. Journal of Abnormal Psychology, 88, 388-397.

Blatt, S. J., \& Wild, C. M. (1976), Schizophrenia: A developmental analysis. New York: Academic Press. 
Blatt, S. J., \& Zuroff, D. (in press). Interpersonal relatedness and self-definition: Two prototypes for depression. Clinical Psychology Review.

Blehar, M. C., Liebermann, A. F., \& Ainsworth, M. (1977). Early face-to-face interactions and its relation to later mother-infant attachment. Child Development, 48, 182-194.

Bohrnstedt, G. W., \& Fisher, G. A. (1986). The effects of recalled childhood and adolescent relationships compared to current role performances on young adults' affective functioning. Social Psychology Quarterly, 49, 19-32.

Bower, G. H. (1981). Mood and memory. American Psychologist, 36, 129-148.

Bowlby, J. (1969). Attachment and loss: Vol. 1. New York: Basic Books.

Bowlby, J. (1973). Attachment and loss: Vol. 2: Separation, anxiety and anger. New York: Basic Books.

Bowlby, J. (1977). The making and breaking of affectional bonds: Part 1. Etiology and psychopathology in light of attachment theory. British Journal of Psychiatry, 130, 201-210.

Bowlby, J. (1980). Attachment and loss: Vol. 3: Loss, separation, and depression. New York: Basic Books.

Bowlby, J. (1988). Developmental psychiatry comes of age. American Journal of Psychiatry, 145, 1-10.

Boyd, J. H., \& Weissman, M. M. (1982). Epidemiology. In E. S. Paykel (Ed.), Handbook of affective disorders. New York: Guilford.

Brewin, C. R., Firth-Cozens, J., Furnham, A., \& Andrews, B. (in press). Self-criticism in adulthood and perceived childhood experience. Journal of Abnormal Psychology.

Brewin, C. R., \& Furnham, A. (1987). Dependency, self-criticism and depressive attributional style. British Journal of Clinical Psychology, 26, 225-226.

Brown, G. W., Sklair, F., Harris, T. O., \& Biriey, J. L. T. (1973). Life events and psychiatric disorders: Part I. Some methodological issues. Psychological Medicine, 3, 74-87.

Bruner, J. (1986). Actual minds, possible worlds. Cambridge, MA: Harvard University Press.

Burbach, D. J., \& Bourdin, C. M. (1986). Parent-child relations and the etiology of depression: A review of methods and findings. Clinical Psychology Review, 6, 133-153.

Cadoret, R. J., Winkur, G., Dorzab, J., \& Baker, M. (1972). Depressive disease: Life events and onset of illness. Archives of General Psychiatry, 26, 133-136.

Cane, D. B., Olinger, L. J., Gotlib, I. H., \& Kuiper, N. A. (1986). Factor structure of the Dysfunctional Attitude Scale in a student population. Journal of Clinical Psychology, 42, 307-309.

Cantwell, D. P. (1983). Family genetic factors. In D. P. Cantwell \& G. A. Carlson (Eds.), Affective disorders in childhood and adolescence (pp. 3-18). New York: Spectrum.

Cantwell, D. P., \& Carlson, G. A. (1983). Affective disorders in childhood and adolescence. New York: Spectrum.

Chevron, E. S., Quinlan, D. M., \& Blatt, S. J. (1978). Sex roles and gender differences in the experience of depression. Journal of Abnormal Psychology, 87, 680-683.

Cicchetti, D., \& Aber, J. L. (1986). Early precursors of later depression: An organizational perspcctive. In L. Lipsett (Ed.), Advances in infancy research (Vol. 3; pp. 87-137). Norwood, NJ: Ablex.

Cicchetti, D, \& Schneider-Rosen, K. (1984a). Theoretical and empirical considerations in the investigation of the relationship between affect and cognition in atypical populations of infants. Contributions to the formulation of an integrative theory of development. In D. Izard, J. Kagan, \& R. Zajoric (Eds.), Emotions, cognitions and behavior (pp. 366-406). New York: Cambridge University Press.

Cicchetti, D., \& Schneider-Rosen, K. (1984b). Toward a transactional model of childhood depression. In D. Cicchetti \& K. Schneider-Rosen (Eds.), Childhood depression (pp. 5-28). San Francisco: Jossey-Bass.

Cicchetti, D., \& Sroufe, L. A. (1978). An organizational view of affect. Illustration from the study of Down's syndrome infants. In M. Lewis \& L. Rosenblum (Eds.), The development of affect (pp. 309-350). New York: Plenum.

Cohen, M. B., Baker, G., Cohen, R. A., Fromm-Reichman, F., \& Weight, E. V. (1954). An intensive study of twelve cases of manic-depressive psychosis. Psychiatry, 17, 103-137.

Cohn, J. F., Campbell, S. B., Matias, R., \& Hopkins, J. (1990). Facc-to-facc interactions of postpartum depressed and nondepressed mother-infant pairs at 2 months. Developmental Psychology, 26, 15-23.

Cohn, J. F., Matias, R., Tronick, E. Z., Connell, D., \& Lyons-Ruth, K. (1986). Face to face interactions of depressed mothers and their infants. In E. Z. Tronick \& T. Field (Eds.), Maternal depression and infant disturbance. (New directions for child development, No. 34) (pp. 31-45). San Francisco: Jossey-Bass.

Cohn, J. F., \& Tronick, E. Z. (1983). Three-month-old infants' reactions to simulated maternal depression. Child Development, 54, 185-193.

Cohn, J. F., \& Tronick, E. Z. (1987). Mother-infant face-to-face interaction: The sequence of dyadic states at 3, 6, and 9 months. Developmental Psychology, 23, 68-77.

Coyne, J. C., Kahn, J., \& Gotlib, I. H. (1987). Depression: In T. Jacob (Ed.), Family interaction and psychopathology (pp. 509-534). New York: Plenum.

Crook, T., Raskin, A., \& Elliott", J. (1981). Parent-child relationships and adult depression. Child Development, 52, 950-957. 
Cytryn, L., McKnew, D. H., Zahn-Waxler, C., Radke-Yarrow, M., Gaensbauer, T. J., Harmon, R. J., \& Lamour, M. (1984). A developmental view of affective disturbances in the children of affectively ill parents. American Journal of Psychiatry, 141, 219-222.

Davenport, Y. B., Zahn-Waxler, C., Adland, M. L., \& Mayfield, A. (1984). Early childrearing practices in families with manic depressive parents. American Journal of Psychiatry, 141, 230-235.

Dweck, C. S., \& Licht, B. (1980). Learned helplessness and intellectual achievement. In J. Garber \& M. E. P. Seligman (Eds.), Human helplessness (pp. 197-221). New York: Academic Press.

Egeland, B., \& Sroufe, L. A. (1981). Attachment and early maltreatment. Child Development, 52, 44-52.

Emde, R. N., Harmon, L., \& Good, W. V. (1986). Depressive feelings in children: A transactional model for research. In M. Rutter, C. E. Izard, \& P. B. Read (Eds.), Depression in young people: Developmental and clinical perspectives (Pp. 135-160). New York: Guilford.

Endicott, J., \& Spitzer, R. L. (1978). A diagnostic interview: The schedule for affective disorders and schizophrenia. Archives of General Psychiatry, 35, 837-844.

Erickson, M. F., Sroufe, L. A., \& Egeland, B. (1985). The relationship between quality of attachment and behavior problems in preschool in a high risk sample. Monographs of the Society for Research in Child Development, 50, $147-166$.

Erikson, H. (1963). Childhood and society (2nd ed.). New York: W. W. Norton.

Faravelli, C., Sacchetti, E., Ambonetti, A., Conte, G., Pallanti, S., \& Vita, A. (1986). Early life events and affective disorder revisited. British Journal of Psychiatry, 148, 288-295.

Feather, N. T. (1966). Effects of prior success and failure on expectations and subsequent performance. Journal of Personality and Social Psychology, 3, 278-298.

Field, T. M. (1984). Early interactions between infants and their postpartum depressed mothers. Infants Behavior and Development, 7, 527-532.

Field, T. M., Healy, B., Goldstein, S., \& Guthertz, M. (1990). Behavior-state matching and synchrony in mother-infant interactions of nondepressed versus depressed dyads. Developmental Psychology, 26, 7-14.

Field, T. M., Healy, B., Goldstein, S., Perry, S., Bendell, D., Schanberg, S., Zimmerman, E. A., \& Kuhn, C. (1988). Infants of depressed mothers show "depressed" behavior even with nondepressed adults. Child Development, 59, 1569-1579.

Fishler, P. H., Sperling, M. B., \& Carr, A. C. (1990). Assessment of adult relatedness: A review of empirical findings from object relations and attachment theories. Journal of Personality Assessment, 55, 499-520.

Fiske, S. T., \& Linville, F. W. (1980). What does the schema concept buy us? Personality and Social Psychology Bulletin, 6, 543-557.

Fonseca, E. (1987). A study of anaclitic depression using the subliminal psychodynamic activation method. Unpublished master's thesis, New York University.

Forrest, A. D., Fraser, R. H., \& Priest, R. G. (1965). Environmental factors in depressive illness. British Journal of Psychiatry, 111, 243-253.

Fraiberg, S. (1969). Libidinal object constancy and mental representation. Psychoanalytic Study of the Child, 24, $9-47$.

Freud, S. (1900). The interpretation of dreams. In J. Strachey (Ed. and Trans.), The standard edition of the complete psychological works of Sigmund Freud (Vols. 4 \& 5). London: Hogarth Press.

Freud, S. (1914). On narcissism: An introduction. In J. Strachey (Ed. and Trans.), The standard edition of the complete psychological works of Sigmund Freud (Vol. 14, pp. 73-102). London: Hogarth Press.

Freud, S. (1930). Civilization and its discontents. In J. Strachey (Ed. and Trans.), The standard edition of the complete psychological works of Sigmund Freud (Vol. 21, pp. 64-145). London: Hogarth Press.

Friedman, R. C., Corn, R., Hurt, S. W., Fibel, B., Schulick, J., \& Swirsky, S. (1984). Family history of illness in the seriously suicidal adolescent: A life cycle approach. American Journal of Orthopsychiatry, 54, 39703971.

Gacnsbauer, T. (1982). Regulation of emotional expression in infants from two contrasting caretaker environments. Journal of the American Academy of Child Psychiatry, 141, 223-229.

Gaensbauer, T. J., Harmon, R. J., Cytryn, L., \& McKnew, D. H. (1984). Social and affective development in infants with a manic-depressive parent. American Journal of Psychiatry, 141, 223-229.

Garber, J. (1984). Classification of developmental psychopathology: A developmental perspective. Child Development, $55,30-48$

Gardner, H. (1984). The mind's new science: $A$ history of the cognitive revolution. New York: Basic Books.

Garmezy, N. (1987). Developmental changes in response to stress. In M. Rutter, C. E. Izard, \& P. B. Read (Eds.), Depression in young people (pp. 297-323). New York: Guilford.

Garrison, C. (1982). Depression sympioms, family environment, and life change in early adolescents. Unpublished doctoral dissertation, University of Nurth Carulina at Chapel Hill.

Gelinas, D. J. (1983). The persisting negative effects of incest. Psychiatry, 46, 312-331. 
Gershon, E., Bunney, W. E., Leckman, J. F., Van Eerdewegh, M., \& DeBauche, B. A. (1976). The inheritance of affective disorders: A review of data and hypotheses. Behavior Geneitcs, 6, 227-261.

Gold, E. R. (1986). Long-term effects of sexual victimization in childhood: An attributional approach. Journal of Consulting and Clinical Psychology, 54, 471-475.

Goodman, N. (1984). Of mind and other matters. Cambridge, MA: Harvard University Press.

Goodnian, S. H., \& Brumley, H. E. (1990). Schizophrenic and depressed parents: Relational deficits in parenting. Developmental Psychology, 26, 31-39.

Gotlib, I. H., Mount, J. H., Cordy, N. I., \& Whiffen, N. E. (1988). Depression and perceptions of early parenting: A longitudinal investigation. British Journal of Psychiatry, 152, 24-27.

Gove, W. R. (1982). Labelling theory's explanation of mental illness: An update of recent evidence. Deviant Behavior, 3, 307-327.

Graham, S., Doubleday, C., \& Guarino, P. A. (1984). The development of relations between perceived controllability and the emotions of pity, anger, and guilt. Child Development, 55, 561-565.

Hammen, G., Burge, D., \& Stansbury, K. (1990). Relationship of mother and child variables to child outcomes in a high-risk sample: A causal modeling analysis. Developmental Psychology, 26, 24-30.

Hammen, C., Marks, T., deMayo, R., \& Mayol, A. (1985). Self-schemas and risk for depression: A prospective study. Joumal of Personality and Social Psychology, 49, 1147-1159.

Harder, S. (1978). Effectance motivation reconsidered: Toward a developmental model. Human Development, $21,34-64$

Hastie, R. (1981). Schematic principles in human memory. In E. T. Higgins, P. Herman, \& M. P. Zanne (Eds.), Social cognition: The Ontario symposium (pp. 39-88). Hillsdale, NJ: Lawrence Erlbaum Associates.

Hazan, C., \& Shaver, P. C. (1990). I ove and work: An attachment-theoretical perspective. Journal of Personality and Social Psychology, 59, 270-280.

Hazan, C., \& Shaver, P. C. (1987). Romantic love conceptualized as an attachment process. Journal of Personality and Social Psychology, 52, 511-524.

Higgins, E. T. (1987). Self-discrepancy: A theory relating self and affect. Psychological Revizw, 94, 319-340.

Higgins, E. T. (1989). Continuities and discontinuities in self-regulatory and self-evaluative processes: A developmental theory relating self and affect. Journal of Personality, 57, 407-444.

Hirsch, B. J., Moos, R. H., \& Reischl, T. M. (1985). Psychosocial adjustment of adolescent children of a depressed, arthritic or normal parents. Journal of Abnormal Psychology, 94, 154-164.

Hirschfeld, R., Klerman, G. L., Chodoff, P., Korchin, S., \& Barrett, J. (1976). Dependency, self-esteem and clinical depression. Journal of the American Academy of Psychoanalysis, 4, 373-388.

Hirschfeld, R., Klerman, G. L., Gough, H. G., Barrett, J., Korchin, S. J., \& Chodoff, P. (1977). A measure of interpersonal dependency. Journal of Personality Assessment, 41, 610-618.

Hudgeons, R., Morrison, J., \& Rarchha, R. (1967). Life events and onset of primary affective disorders. Archives of General Psychiatry, 16, 134-145.

Isen, A., Shakler, T., Clark, M., \& Karp, L. (1978). Affect accessibility of material in memory and behavior: A cognitive loop? Joumal of Personality and Social Psychology, 36, 1-12.

Jacobson, S., Fasman, J., \& DiMascio, A. (1975). Deprivation in the childhood of depressed women. Joutnal of Nervous and Mental Disease, 160, 5-14.

Johnson, J. E., Petzel, T. P., Dupont, M. P., \& Romano, B. M. (1982). Phenomenological perceptions of parental evaluations in depressed and nondepressed college students. Journal of Clinical Psychology, 38, 56-62.

Kagan, G. (1981). The second year. Cambridge, MA: Harvard University Press.

Kashani, J. H., Burk, J. P., \& Reid, J. C. (1985). Depressed children of depressed parents. Canadian Journal of Psychiatry, 30, 265-268.

Kashani, J. H., Husain, A., Shokim, W. O., Hodges, K. K., Cytryn, L., \& McKnew, D. H. (1981). Current perspectives on childhood depression: An overview. American Journal of Psychiatry, 138, 143-153.

Kashani, J. H., McGee, R. O., Clarkson, S. F., Anderson, J. C., Walton, L. A., Williams, S., Silva, P. A., Robins, A. J., Cytryn, L., \& McKnew, D. H. (1983). The nature and prevalence of major and minor depression in a sample of nine-year-old children. Archives of General Psychiatry, 40, 1217-1227.

Klagsbrun, M., \& Bowlby, J. (1976). Responses to separation from parents: A clinical test for young children. British Journal of Projective Pychology, 21, 2-27.

Kobak, R. R., \& Sceery, A. (1988). Attachment in late adolescence: Working models affect regulations, and perception of self and others. Child Development, 59, 135-146.

Koestner, R., Zuroff, D. C., \& Powers, T. A. (1991). The family origins of adolescent self-criticism and its continuity into adulthood. Journal of Abnormal Psychology, 100, 191-197.

Koufopoulos, R. M. (1986). A study of introjectioe depression using the subliminal psychodynamic activation method. Unpublished doctoral dissertation, New York University.

Kovacs, M., Feinberg, T. L., Crause-Novack, M., Paulaskas, S. L., \& Finkelstein, R. (1984). Depressive 
disorders in childhood. I. A longitudinal perspective study of characteristics and recovery. Archives of General Psychiatry, 41, 229-237.

Kovacs, M., Feinberg, 'I. L., Crause-Novack, M., Paulaskas, S. L., Pollock, M., \& Finkelstein, K. (1984). Depressive disorders in childhood. II. A longitudinal study of the risk for a subsequent major depression. Archives of General Psychiatry, 41, 643-649.

Kuiper, N. A., \& MacDonald, M. R. (1982). Self and other perception in mild depressives. Social Cognition, 1, 223-239.

Lamont, J., Fischoff, J., \& Gottlieb, H. (1976). Recall of parental behavior in female neurotic depressives. Journal of Clinical Psychology, 32, 762-765.

Lamont, J., \& Gottlieb, H. (1975). Convergent recall of parental behaviors in depressed students of different racial groups. Journal of Clinical Psychology, 31, 9-11.

Lesse, S. (1974). Masked depression. New York: Aronson.

Lewinsohn, P. M., \& Rosenbaum, M. (1987). Recall of parental behavior by acute depressives, remitted depressives and non-depressives. Journal of Personality and Social Psychology, 52, 611-619.

Lewis, H. B. (1990). Shame, repression, field dependency and psychopathology. In J. L. Singer (Ed.), Repression and dissociation: Implications for personality theory, psychopathology and health (pp. 233-257). Chicago: University of Chicago Press.

Lloyd, C. (1980). Life events and depressive disorders reviewed. Archives of General Psychiatry, 37, 541-548.

Londerville, S., \& Main, M. (1981). Security of attachment, compliance, and maternal training methods in the second year of life. Developmental Psychology, 17, 289-299.

Mahler, M. S., Pine, F., \& Bergman, A. (1975). The psychological birth of the human infant. New York: Basic Bonks.

Main, M. (1981). Avoidance in the service of attachment: A working paper. In K. Immelman, G. Barlow, L. Petrinovich, \& M. Main (Eds.), Behavioral development: The Bielfeld Interdisciplinary Project (pp. 651-693). New York: Cambridge University Press.

Main, M. (1983). Exploration, play, and cognitive functioning related to infant-mother attachment. Infant Behavior and Development, 6, 167-174.

Main, M. (1990, April). Meta-cognitive knowledge, meta-cognitive monitoring and attachment: Some findings and some directions for future research. Plenary address to the Michigan Association for Infant Mental Health, Ann Arbor, MI.

Main, M., \& Goldwyn, R. (1984). Predicting rejection of her infant from mother's representation of her own experience. Implications for the abused-abusing intergenerational cyclc. Child Abuse and Neglect, 8, 203217.

Main, M., Kaplan, N., \& Cassidy, J. (1985). Security in infancy, childhood and adulthood: A move to the level of representation. In $\mathrm{I}$. Bretherton \& $\mathrm{F}$. Waters (Eds.), Growing points in attachment theory and research (Vol. 50, Society for Research in Child Development Monographs; pp. 66-104). Chicago: Chicago University Press.

Main, M., \& Weston, D. R. (1981). The quality of the toddler's relationship to mother and father: Related to conflict behavior and the readiness to establish new relationships. Child Development, 52, 932-940.

Matas, L., Arend, R., \& Sroufe, L. A. (1978). Continuity and adaptation in the second year. The relationship between quality of attachment and later competence. Child Development, 49, 547-556.

Matussek, P., \& Feil, W. B. (1983). Personality attributes of depressive patients. Archives of General Psychiatry, 40, 783-790.

Matussek, P., Molitor, G. A., \& Seibt, G. (1985). Childhood experiences of endogenous and neurotic depressives. European Archives of Psychiatry and Neurological Sciences, 235, 12-20.

McAdams, D. P. (1985). Power, intimacy, and the life story: Personological inquiries into identity. Homewood, IL: Dorsey.

McCranie, C. W., \& Bass, J. D. (1984). Childhood family antecedents of dependency and self-criticism: Implications for depression. Journal of Abnormal Psychology, 93, 3-8.

Miller, G., Galanter, E., \& Pribram, K. (1960). Plans and the structure of behavior. New York: Holt, Reinhart, \& Winston.

Mongrain, S., \& Zuroff, D. C. (1989). Cognitive vulnerability to depressed affect independent and self-critical women. Journal of Personality Disorders, 3, 240-251.

Neisser, U. (1967). Cognitive psychology. New York: Appleton-Gentury-Croft.

Neisser, U. (1976). Cognition and reality. San Francisco: W. H. Freeman.

Orvaschel, H., Weissman, M. M., \& Kidd, K. K. (1980). Children and depression: The children of depressed parents: The childhood of depressed patients; Depression in children. Journal of Affective Disorders, 2, 1-16.

Osgood, C. E., Suci, G. J., \& Tannenbaum, P. H. (1957). The measurement of meaning. Urbana: University of Illinois Press. 
Owen, M. T., Easterbrooks, M. A., Chase-Landsdale, L., \& Goldberg, W. A. (1984). The relationship between matemal employment status and stability of attachments to mother and to father. Child Development, $55,1894-1901$.

Parker, G. (1979a). Parental characteristics in relation to depressive disorders. British Journal of Psychiatry, 134, $138-147$.

Parker, G. (1979b). Reported parental chatacteristics in relation to uait depression and anxiely levels in a non-clinical group. Australian and New Zealand Joumal of Psychiatry, 13, 260-264.

Parker, G. (1980). Vulnerability factors to normal depression. Journal of Psychosomatic Research, 24, 67-74.

Parker, $G$. (1981). Parental reports of depressives: An investigation of several explanations. Journal of Affective Disorders, 3, 131-140.

Parker, G. (1982). Parental representations and affective symptoms: Examination for an hereditary link. British Journal of Medical Psychology, 55, 57-61.

Parker, G. (1983). Parental "affectionless control" as an antecedent to adult depression: A risk factor delineated. Archites of General Psychiatry, 40, 956-960.

Parker, G. (1984). The measurement of pathogenic parental style and its relevance to psychiatric disorder. Social Psychiatry, 19,75-81.

Parker, G., \& Hadzi-Pavlovic, D. (1984). Modification of levels of depression in mother-bereaved women by parental and marital relationships. Psychological Medicine, 14, 125-135.

Parker, G., \& Lipscombe, P. (1980). The relevance of early parental experiences to adult dependency, hypochondriasis and utilization of primary physicians. British Journal of Medical Psychology, 53, 355-363.

Parker, G., Tupling, H., \& Brown, L. B. (1979). A Parental Bonding Instrument. British Journal of Medical Psychology, 52, 1-10.

Paykel, E. S. (1982). Life events and early environment. In E. S. Paykel (Ed.), Handbook of affective disorders (pp. 146-161). London: Churchill-Livingstone.

Paykel, E. S., Meyers, J. K., Dienelt, M. N., Klerman, G. L., Lindenthal, J. T., \& Pepper, M. N. (1969). Life events and depression. Archives of General Psychiatry, 21, 753-760.

Paykel, E. S., Prusoff, B. A., \& Meyers, J, K. (1975). Suicide attempts and recent life events: A controlled comparison. Archives of General Psychiatry, 32, 327-333.

Paykel, E. S., \& Tanner, J. (1976). Life events, depressive relapses and maintenance treatment. Psychological Medicine, 6, 481-485.

Perris, C., Arrindell, W. A., Perris, H., Eisemann, M., Van der Ende, J., \& Von Knorring, L. (1986). Perceived depriving parental rearing and depression. British Joumal of Pychiaty, 148,170-175.

Peterson, C., Schwartz, S. M., \& Seligman, M. E. P. (1984). Self-blame and depressive symptoms. Journal of Personality and Social Psychology, 41, 253-259.

Peterson, C., \& Seligman, M. E. P. (1984). Causal explanations as a risk factor for deprcssion: Theory and evidence. Psychological Review, 91, 347-374.

Piaget, J. (1954). The construction of reality in the child (M. Cook, Trans.). New York: Basic Books. (Original work published 1937)

Piaget, J. (1962). Play, dreams and imitation in childhood (C. Gattegno \& F. M. Hodgson, Trans.). New York: W. W. Norton. (Original work published 1945)

Pine, F. (1974). Libidinal object constancy: A theoretical note. Psychoanalysis and Contemporary Science, 4, 307-313.

Quinlan, D. M., Blatt, S. J., Chevron, E. S., \& Wein, S. (in press). Parental descriptions: Factorial composition, reliability and validity of refined rating procedures. Journal of Personality Assessment.

Radke-Yarrow, M., Cummings, E. M., Kuczyinski, L., \& Chapman, M. (1985). Patterns of attachment in two and three-year-olds in normal families and families with parental depression. Child Development, 56, 884893.

Raskin, A., Boothe, H. H., Reatig, N. A., Schulterbrandt, J. G., \& Odle, D. (1971). Factor analyses of normal and depressed patients' memories of parcntal bchavior. Psychological Reports, 29, 871-879.

Reich, M. (1988). The prediction of social interaction at two years from mother-infant interaction at four months. Unpublished doctoral dissertation, Yeshiva University, New York, NY.

Richman, J. A., \& Flaherty, J. A. (1987). Adult psychosocial assets and depressive mood over time: Fiffects of internalized childhood attachments. Journal of Nervous and Mental Disease, 175, 703-712.

Robins, C. J. (1985). Effects of stimulated social reflection and achievement failure on mood as a function of socioiropy and autonomous personality characteristics. Unpublished manuscript.

Robins, C. J., \& Block, P. (1988), Personal vulnerability, life events, and depressive symptoms: A test of a specific interactional model. Journal of Personality and Social Psychology, 54, 847-852.

Rutter, M. (1986). The developmental psychopathology of depression: Issues and perspectives. In M. Rutter, C. Lzard, \& P. Read (Eds.), Depression in Young People: Developmental and clinical perspectives (pp. 3-30). New York: Guilford. 
Rutter, M. (1990). Commentary: Some focus and process considerations regarding effects of parental depression on children. Developmental Psychology, 26, 60-67.

Rutter, M., Izard, C. E., \& Reed, P. B. (1986). Depression in young people: Development and clinical perspectives. New York: Guilford.

Sameroff, A., \& Chandler, M. (1975). Reproductive risk and the continuum caretaking casualty. In F. Horowitz (Ed.), Review of child development research (Vol. 4; Pp. 187-244). Chicago: University of Chicago Press.

Sameroff, A. J., Seifer, R., \& Zax, M. (1982). Early development of children at risk for emotional disorder. Chicago: University of Chicago Press.

Sandler, J., Holder, A., \& Meers, D. (1963). The ego ideal and the ideal self. Psychoanalytic Study of the Child, 18, 139-158.

Schaefer, E. S. (1965). Children's reports of parental behavior: An inventory. Child Development, 36, 413-424.

Schaffer, C. E., \& Blatt, S. I. (1990). Interpersonal relationships and the experience of perceived efficacy. In R. J. Sternberg \& J. Kolligian, Jr. (Eds.), Perceptions of competence and incompetence across the lifespan (pp. 229 245). New Haven, CT: Yale University Press.

Schneider-Rosen, K., \& Cicchetti, D. (1984). The relationship between affect and cognition in maltreated infants: Quality of attachment and the development of self recognition. Child Develoment, 55, 648-658.

Schwarz, J. C., \& Zuroff, D. (1979). Family structure and depression in female college students: Effects of parental conflict, decision making power, and inconsistency of love. Journal of Abnormal Psychology, 88, 398406.

Seligman, M. E. P. (1975). Helplessness: On depression, development and death. San Francisco: W. H. Freeman.

Seligman, M. E. P., Peterson, C., Kaslow, N. J., Tanenbaum, R. L., Alloy, L. B., \& Abramson, L. Y. (1984). Explanatory style and depressive symptoms among children. Journal of Abnormal Psychology, 93, 235238.

Shank, R. C., \& Abelson, R. (1977). Scripts, plans, goals and understanding. Hillsdale, NJ: Lawrence Erlbaum Associates.

Shaver, P. C., \& Hazan, C. (1987). Being lonely, falling in love: Perspectives from attachment theory, Journal of Social Behavior and Personality, 2, 105-124.

Shor, J,, \& Sanville, J. (1978). Illusions in loving: A pyychoanalytic approach io intimacy and autonomy. Los Angeles: Double Helix.

Silverman, L. H. (1966). A technique for the study of psychodynamic relationships: The effects of subliminally presented aggressive stimuli on the production of pathological thinking in a schizophrenic population. Journal of Consulting and Clinical Psychology, 30, 103-111.

Spiegel, H., \& Spiegel, D. (1978). Trance and treatment: Clinical uses of hypnosis. New York: Basic Books.

Sroufe, L. A. (1983). Infant-caregiver attachment and patterns of attachment in pre-school: The roots of maladaptivc competence. In M. Perlmutter (Ed.), Mintesota symposium on child psychology (Vol. 16; pp. 4183). Hillsdale, NJ: Lawrence Erlbaum Associates.

Stern, D. N. (1985). The psychological world of the infant. New York: Basic Books

Stolorow, R. D. (1978). The concept of psychic structure: Its metapsychological and clinical psychoanalytic meanings. International Review of Psychoanalysis, 5, 313-320.

Taylor, S. E., \& Crocker, J. (1987). Schematic bases of social information processing. In E. T. Higgins, C. P. Herman, \& M. P. Zanna (Eds.), Social cognition: The Ontario sympositum on personality and social psychology (pp. 89-134). Hillsdale, NJ: Lawrence Erlbaum Associates.

Teasdale, J. D., Taylor, R., \& Fogarty, S. J. (1980). Effects of induced elation-depression on the accessibility of memories of happy and unhappy experiences. Behaviour Research and Therapy, 18, 339-346.

Thompson, K. C., \& Hendrie, H. C. (1972). Environmental stress in primary depressive illness. Archives of General Psychiatry, 26, 130-132.

Thompson, R. A., Lamb, M. E., \& Estes, D. (1982). Stability of infant mother attachment and its relationship to changing life circumstances in an unselected middle class sample. Child Development, 53, 144 148.

Tronick, E. Z., \& Gianino, A. (1986). The transmission of maternal disturbance to the infant. In E. Z. Tronick \& T. Field (Eds.), Maternal depression and infant disturbance (New Directions for Child Development, No. 34) (pp. 5-12). San Francisco: Josey-Bass.

Vaughn, B., Egeland, B., Sroufe, L. A., \& Waters, E. (1979). Individual differences in infant mother attachment at twelve and eighteen months: Stability and change in infant mother attachment in families under stress. Child Development, 50,971-975.

Waters, E. (1978). The reliability and stability of individual differences in infant-mother attachment. Child Development, $\mathbf{5 0}, 821-829$.

Waters, E., Wippman, J., \& Sroufe, L. A. (1979). Attachment, positive affect and competence in the peer group; Two studies in construct validation. Child Development, 50, 821-829.

Weissman, A. N., \& Beck, A. T. (1978). Development and validation of the Dysfunctional Attitude Scale: A preliminary investigation. Presented at meetings of the American Psychological Association, Toronto, Canada. 
Weissman, M. M., Gammen, G. D., John, K., Merikangas, K. R., Warner, V., Prusoff, B. A., \& Sholomskas, D. (1987). Children of depressed parents: Increased psychopathology and early onset of depression. Archives of General Psychiatry, 44, 847-853.

Werner, H. (1948). Comparative psychology of mental development. New York: International Universities Press.

West, M., \& Sheldon, A. E. R. (1988). Classification of pathological attachment patterns in adults. Journal of Personality Disorders, 2, 153-159.

West, M., Sheldon, A. E. R., \& Reiffer, L. (1987). An approach to the delineation of adult attachment: Scale development and reliability. Journal of Nervous and Mental Disease, 175, 738-741.

Wetzel, J. W. (1978). The work environment and depression: Implications for intervention. In J. W. Hanks (Ed.), Toward human dignity: Social work in practice (Pp. 236-245). New York: National Association of Social Workers.

Wetzel, J. W., \& Redmond, P. C. (1980). A person-environment study of depression. Social Service Review, 54, 363-375.

Yarrow, L. J., \& Goodwin, M. S. (1973). The immediate impact of separation: Reactions of infants to a change in mother figures. In J. Stone, H. T. Smith, \& C. B. Murphy (Eds.), The competent infant (pp. 10321040). New York: Basic Books.

Zahn-Waxler, C., Kochanska, G., Krupnick, J., \& McKnew, D. (1990). Patterns of guilt in children of depressed and well mothers. Developmental Psychology, 26, 51-59.

Zahn-Waxler, G., McKnew, D. II., Cummings, E. M., \& Radke-Yarrow, M. (1984). Problem behaviurs and peer interactions of young children with a manic depressive parent. Child Development, 55, 112-122.

Zelnick, L., \& Buchholz, E. S. (1990). The concept of mental representations in light of recent infant research. Psychoanalytic Psychology, 7, 29-58.

Zung, W. W. (1972). How normal is depression? Psychosomatics, 13, 173-178.

Zuroff, D., Quinlan, D. M., \& Blatt, S. J. (1990). Psychometric properties of the Depressive Experiences Questionnaire. Journal of Personality Assessment, 55, 65-72.

Received March 15, 1990

Accepted December 13, 1990 